\title{
Finite Element Modelling of Load Bearing Cold-formed Steel Wall Systems under Fire Conditions
}

\author{
Shanmuganathan Gunalan and Mahen Mahendran
}

\begin{abstract}
Light Gauge Steel Framing (LSF) walls are made of cold-formed, thin-walled steel lipped channel studs with plasterboard linings on both sides. However, these thin-walled steel sections heat up quickly and lose their strength under fire conditions despite the protection provided by plasterboards. A new composite wall panel was recently proposed to improve the fire resistance rating of LSF walls, where an insulation layer was used externally between the plasterboards on both sides of the wall frame instead of using it in the cavity. A research study using both fire tests and numerical studies was undertaken to investigate the structural and thermal behaviour of load bearing LSF walls made of both conventional and the new composite panels under standard fire conditions and to determine their fire resistance rating. This paper presents the details of finite element models of LSF wall studs developed to simulate the structural performance of LSF wall panels under standard fire conditions. Finite element analyses were conducted under both steady and transient state conditions using the time-temperature profiles measured during the fire tests. The developed models were validated using the fire test results of $11 \mathrm{LSF}$ wall panels with various plasterboard/insulation configurations and load ratios. They were able to predict the fire resistance rating within five minutes. The use of accurate numerical models allowed the inclusion of various complex structural and thermal effects such as local buckling, thermal bowing and neutral axis shift that occurred in thin-walled steel studs under non-uniform elevated temperature conditions. Finite element analyses also demonstrated the improvements offered by the new composite panel system over the conventional cavity insulated system.
\end{abstract}

Keywords: Light gauge steel frame walls, Plasterboards, Insulation, Steel studs, Composite Panels, Standard fire, Elevated temperatures, Load bearing walls, Finite element analyses, Fire resistance rating. 


\section{Introduction}

Cold-formed lipped channel sections are commonly used as load bearing wall studs in light gauge steel frames (LSF) lined with plasterboards (Figure 1 (a)). Under fire conditions, these thin-walled steel sections (high section factor) heat up quickly resulting in a rapid reduction to their strength and stiffness despite the protection offered by fire rated plasterboards. Fire resistance rating of LSF wall systems depends on many parameters such as LSF wall configurations (details of plasterboard linings, insulations and their layouts), geometry of LSF wall studs and load ratio. It is important that fire engineers have a good understanding of the fire behaviour and fire resistance rating (FRR) of LSF wall systems and access to simpler design methods capable of predicting their FRR.

The fire behaviour of LSF wall panels has been investigated by many researchers in the past [1-9]. The fire-resistance rating of these wall panels were assigned based on standard fullscale fire tests $[1-4,8,9]$ although a few numerical studies were also performed to simulate the structural performance of LSF wall panels subjected to standard fire conditions $[2,4,5,7,9]$. Feng et al.'s [6] tests showed that the interior (cavity) insulation improved the fire resistance of LSF wall panels while other studies $[3,4]$ revealed that wall assemblies without cavity insulation provided higher fire resistance than cavity insulated assemblies. There is limited data available on the thermal performance of non-load bearing and load bearing LSF wall systems and past research has often provided contradicting results about the benefits of cavity insulation to the fire rating of LSF wall systems. Further, past research on LSF wall systems has mostly been limited to LSF wall systems used in the UK, USA and Canada. The LSF wall systems used in Australia are made of thinner and high strength steels and protected by Australian plasterboards, and their fire behaviour has not been investigated in detail. The Australian building industry is also interested in developing new LSF wall systems with higher fire resistance rating. Therefore a detailed research program was undertaken to investigate the fire performance of Australian LSF wall systems and to develop LSF wall systems with higher FRR. A series of full scale fire tests of LSF walls (Figure 1 (b)) was conducted first to evaluate the FRR of load bearing LSF wall assemblies [10, 11]. One wall specimen was tested to failure under an axial compression load at room temperature while ten wall specimens subjected to a constant axial compression load were exposed to standard fire conditions on one side to evaluate their fire performance (Table 1). Conventional LSF wall assemblies lined with single or double layers of plasterboard with or without cavity insulation were considered. The insulations used were $90 \mathrm{~mm}$ thick glass, rockwool and cellulose fibres 
with densities of $15.42 \mathrm{~kg} / \mathrm{m}^{3}, 100 \mathrm{~kg} / \mathrm{m}^{3}$ and $100-110 \mathrm{~kg} / \mathrm{m}^{3}$, respectively. A new LSF wall system based on a composite panel was also proposed in which the insulation was sandwiched between two plasterboards and this composite panel was used on both sides of the wall frame instead of cavity insulation (Tests 1 to $3,6^{*}$ and $7^{*}$ in Table 1 ). This externally insulated LSF wall system was also tested using $25 \mathrm{~mm}$ thick glass, rockwool and cellulose fibres on each side. Since the LSF walls were subjected to fire on one side, nonuniform time-temperature distributions developed across the thickness of LSF wall system as shown in Figure 2 (a). The hot and cold flange temperatures in Figure 2 (a) show that the thin-walled studs are subjected to varying levels of non-uniform temperature distributions with time. The ambient side temperature of the fire side plasterboards develop in three phases as seen in Figure 2 (b). In the first phase the temperature rises quickly to about $100^{\circ} \mathrm{C}$ while in the second phase, it is maintained at about $100^{\circ} \mathrm{C}$ due to the energy consumed in converting the free and chemically bound water present in the plasterboard into steam. In the third phase, it increases again. Hence the thin-walled steel studs attached to these plasterboards are protected from a rapid temperature rise in fires (compare temperatures of surfaces 1 and 2 measured during tests in Figure 2 (b)). This means the load-bearing studs will be able to survive the fire for a longer period, that is, higher fire resistance rating.

Performing full scale fire tests of LSF walls is very difficult, expensive and time consuming. Therefore finite element analyses (FEA) have also been used by many researchers to study the behaviour of LSF wall systems under fire conditions and to determine their FRR $[5,7,9]$. In this research also, detailed numerical studies were undertaken based on suitable finite element models of LSF walls that were validated using the available full scale fire test results $[10,11]$. Such validated finite element models can be used to simulate the behaviour of LSF walls under fire conditions. This approach will considerably improve the efficiency and effectiveness of this research into the complex structural and fire behaviour of LSF walls.

Finite element models of load bearing LSF walls under fire conditions were developed in two stages. A suitable model of LSF wall stud subject to an axial compression load with appropriate thermal and structural boundary conditions was considered adequate to simulate the behaviour of LSF walls. The plasterboards do not share any axial compression load applied to the LSF walls and hence they do not need to be included in the model. However, their structural restraining and thermal protection effects must be considered. Such a model of LSF wall studs was developed first to simulate its behaviour at ambient temperature. It was 
then extended to simulate the behaviour of LSF wall studs under standard fire conditions as used in full scale fire tests $[10,11]$ and to determine the FRR. Figure 2 shows that LSF wall studs are subject to a non-uniform temperature distribution when the wall was subject to standard fire conditions defined in AS 1530.4 [12]. This was considered in the finite element modelling of studs under fire conditions. The finite strip analysis program, CUFSM [13], was used for elastic buckling analyses of LSF wall studs at ambient temperature while the finite element program ABAQUS [14] was used for both elastic buckling and nonlinear analyses under ambient and fire conditions. This paper presents the details of the numerical study of many load-bearing LSF wall systems with varying plasterboard/insulation configurations under standard fire conditions, and the results.

\section{Finite Strip Analyses of LSF Wall Studs at Ambient Temperature}

Elastic buckling analyses of thin-walled members can be undertaken using finite strip analysis programs such as CUFSM [13]. The LSF wall studs used in the fire tests are 1.15 mm thick lipped channels with external dimensions of 90x40x15 mm made of G500 steel (minimum yield stress of $500 \mathrm{MPa}$ ) as shown in Figure 3. Three cases of LSF wall studs shown in Figure 3 were analysed using CUFSM [13]. In Case 1 the LSF wall stud was analysed by ignoring the in-plane lateral restraint provided by the plasterboards while Cases 2 and 3 considered this lateral restraint. Hence the in-plane lateral deflections (UZ) of selected nodes were restrained along the member length. In Case 2, all the flange nodes were restrained whereas only the middle node in each flange was restrained in Case 3.

Figure 4 (a) presents the CUFSM [13] results in the form of Load factor versus half-wave lengths. The load factor shown in Figures 4 (a) and (b) is the elastic buckling load expressed as a ratio of the squash load, which is $127.9 \mathrm{kN}$ for the stud section. The buckling plots for Cases 2 and 3 are about the same, implying that there is negligible difference between restraining one node of the flange versus the entire flange to simulate the in-plane lateral restraints provided by the plasterboard.

When the member length is more than $200 \mathrm{~mm}$, the load factors of the studs in Cases 2 and 3 are much higher compared to that in Case 1. When the member length is less than $1000 \mathrm{~mm}$, the governing load factor is 0.31 with a local buckling mode in all three cases. In the LSF walls tested in our research, the stud length was $2400 \mathrm{~mm}$ (Figure 1) for which the governing 
load factor for Case 1 is 0.12 and the failure mode is flexural-torsional buckling. On the other hand the load factor for Cases 2 and 3 is 0.31 . Figure 4 (b) shows the buckling modes and load factors in all three cases. The governing buckling load factor for a stud length of 2400 $\mathrm{mm}$ is circled in each case.

Figures 4 (a) and (b) clearly demonstrate that the use of plasterboards on both sides of the studs in LSF walls prevents the studs buckling prematurely by a flexural torsional mode (load factor of 0.12). Since the major axis flexural buckling mode (about $\mathrm{Z}$ axis) occurs at a higher load factor of 0.85 for a stud length of $2400 \mathrm{~mm}$, local web buckling with a load factor of 0.31 becomes the critical buckling mode of plasterboard restrained studs in LSF walls.

\section{Finite Element Modelling of LSF Wall Studs}

Many finite element analysis programs are available to predict the structural behaviour of thin-walled members subjected to different actions, and ABAQUS [14] is one of them. ABAQUS [14] was successfully used in the simulation of steel frames and claddings by previous researchers [15-18].ABAQUS [14] will provide accurate results for LSF wall studs provided their loading and boundary conditions and mechanical properties are modelled accurately. Fire resistance ratings of load bearing LSF walls under standard fire conditions is often governed by the structural failure of one or more studs. The studs are subjected to a predetermined load ratio, which is defined as the ratio of the load capacities of studs under fire conditions and at ambient temperature. This research is aimed at determining the fire resistance ratings of various LSF wall systems for a given load ratio, and hence the ambient temperature capacity of LSF wall studs is needed first. Thus a suitable finite element model was developed first to determine the axial compression capacity of LSF wall studs at ambient temperature. It was then extended to simulate the behaviour of LSF wall studs under standard fire conditions. This section presents the details of finite element modelling of LSF wall studs.

\subsection{Element Type and Size}

S4R shell element type with a $4 \mathrm{~mm}$ x $4 \mathrm{~mm}$ mesh size was selected based on detailed convergence studies. The element S4R is a four noded, quadrilateral, stress/displacement shell element with reduced integration and a large-strain formulation. The doubly curved general-purpose shell element S4R gives robust and accurate solutions in most applications 
and allows transverse shear deformations. It provided closer results as S4 elements but with less memory space and time. This element type ensured sufficient degrees of freedom for buckling deformations of LSF wall studs.

\subsection{Mechanical Properties}

The measured mechanical properties were used to enable the comparison of FEA and test results of LSF walls. The measured yield strength and elastic modulus (E) of $1.15 \mathrm{~mm}$ G500 steel used to make the LSF wall studs were $569 \mathrm{MPa}$ and 213,520 $\mathrm{MPa}$, respectively, at ambient temperature [19]. Poisson's ratio of steel was assumed as 0.3. The elastic-perfectplastic material model was used to simulate the LSF wall studs at ambient temperature since the use of this simplified model did not affect the nonlinear behaviour and ultimate load of LSF wall studs.

The mechanical properties at elevated temperatures significantly influence the elastic buckling and ultimate strength behaviour of LSF wall studs because they deteriorate rapidly with increasing temperature. The predictive equations developed in [20] to determine the yield strength and elastic modulus reduction factors were used in the current numerical study since they are more accurate for the cold-formed steels used in Australia. It was shown in [20] that the stress-strain curve model proposed in [21] accurately predicted the stress-strain curves of cold-formed high strength steels. Figure 5 shows the stress-strain curves used in FEA for different temperatures obtained from the equations proposed in [20]. These stressstrain curves were used in the models at elevated temperatures to accurately simulate the effects of reducing mechanical properties at elevated temperatures.

Tensile coupon tests give the nominal stress-strain curves whereas ABAQUS [14] requires a stress-strain relationship in terms of true stress and logarithmic plastic strain. Therefore the engineering stress-strain data obtained from tensile coupon tests ( $\sigma_{\text {eng }}$ and $\varepsilon_{\text {eng }}$ ) were converted to the true stress and logarithmic plastic strain values $\left(\sigma_{\text {true }}\right.$ and $\left.\varepsilon_{\text {true }}^{p l}\right)$ using the following equations [20].

$$
\begin{aligned}
& \sigma_{\text {true }}=\sigma_{\text {eng }}\left(1+\varepsilon_{\text {eng }}\right) \\
& \varepsilon_{\text {true }}^{\text {pl }}=\ln \left(1+\varepsilon_{\text {eng }}\right)-\frac{\sigma_{\text {true }}}{E}
\end{aligned}
$$


Steel will expand considerably when exposed to high temperatures and hence thermal bowing will develop due to the presence of non-uniform temperatures across the stud section (Figure 2 (a)). Thermal elongation is given by Equation 2 [22]. These values were used in the finite element modelling under fire conditions.

$$
\Delta l / l=1.2 \times 10^{-5} T+0.4 \times 10^{-8} T^{2}-2.416 \times 10^{-4} \quad \text { for } 20^{\circ} \mathrm{C} \leq T \leq 750^{\circ} \mathrm{C}
$$

\subsection{Loading and End Support Boundary Conditions}

Appropriate boundary conditions must be included to accurately simulate the behaviour of test specimens. In the tests end plates were used to transfer the load from the hydraulic jacks to the studs via their geometric centroids so that no additional moments were created, ie. pinned end conditions. In all the tests, the central stud that had a vertical plasterboard joint was subjected to more heat flow due to the opening of plasterboard joints (Table 1). Hence the temperature of this critical stud was higher than those of other studs and thus the wall failure was also influenced and initiated by this stud. Based on other numerical studies $[5,7,9]$ and the experimental behaviour of studs $[10,11]$, one of the two central studs that had the vertical plasterboard joint against it was considered in the detailed analyses by taking into account the appropriate loading and boundary conditions as shown in Figure 6.

Kaitila [5] and Feng et al. [7] used a rigid plate at each end of the stud to simulate pinned support conditions. The reference point for the rigid end section was the original centroid of the gross cross-section. Zhao et al. [9] considered two support conditions. In the first case pinned support condition was assumed for both ends whereas in the second case fixed support condition was used in one end while pinned support condition was used at the other end. In our experiments, the end support conditions of LSF wall studs were maintained as pinned. Hence in the numerical study also pinned support conditions were simulated as shown in Figure 6. Rigid plates made of R3D4 elements were attached to each end of the stud, and twisting about these plates (ROTX) was restrained. The ends of the stud were restrained in the two major axial directions (UY and UZ). The axial displacement (UX) was restrained at one end of the member while the axial compressive load was applied at the section centroid at the other end.

\subsection{Plasterboard Restraints}


The simulation of support provided by plasterboards plays a major role in the finite element modelling of LSF wall studs. In our tests $[10,11]$ the plasterboards were found to be effective in restraining the studs from flexural buckling about the minor axis and torsional buckling. Therefore the in-plane lateral restraint provided by the plasterboards was considered on both sides of the studs, that is, it was assumed that the plasterboard on the hot flange side also provided sufficient lateral restraint until the failure of studs. This assumption is the same as used by other researchers $[5,7,9]$ in their finite element models at elevated temperatures.

The connection of steel stud to plasterboard was represented by restraining the lateral displacement (in the plane of wall) of both flanges at $300 \mathrm{~mm}$ intervals along the length. This boundary condition was applied to several regions of the flanges including single node (Case 1) and single row of nodes across the section (Case 2) as shown in Figure 7. Case 1 was used by other researchers [7,9] in their numerical studies of LSF wall studs. Case 3 was simulated with plasterboard restraint applied to a single row of nodes along the length, which is similar to that used in [5]. Case 4 extended Case 1 by including the twist restraint. All these cases resulted in the same elastic buckling load of $39.8 \mathrm{kN}$. The ultimate load was the same for Cases 1 and $2(77.1 \mathrm{kN})$. This indicates that there is negligible difference between restraining one node of the flange and the entire flange. The ultimate loads obtained with Cases 1 and 4 were also the same. This shows that the additional twisting restraint can be ignored. However, Case 3 resulted in a higher ultimate load of $82.9 \mathrm{kN}$. This means that restraining the node along the full length as in [5] will provide a slightly higher ultimate load. Hence either Case 1 or Case 2 can be used to simulate the plasterboard restraint on LSF wall studs. However, Case 1 was used since it represents the actual screw connections between plasterboard and studs.

\subsection{Temperature Distributions}

The accuracy of using two different methods of simplifying the non-uniform temperature distribution observed in LSF wall studs (Figure 8) was investigated in [7]. In Simplification 1 the lip and flange elements had the same temperature with the web having a linear temperature distribution as shown in Figure 8 (a) while in Simplification 2 all the plate elements had a linear temperature distribution (Figure 8 (b)). Feng et al. [7] concluded that Simplification 1 can be used in FEA without affecting the accuracy of the results. On the other hand in the numerical study in [9] the lip temperature was taken as equal to that of the web at the corresponding height. The temperature was assumed to be constant in each flange 
while the web temperature was considered to vary linearly from hot flange to the centre of the web, and then again vary linearly at a slower rate from the centre of the web to the cold flange (Simplification 3 in Figure 8 (c)).

Simplification 1 for the non-uniform temperature distributions in LSF wall studs as proposed in [7] makes it possible to develop hand calculation methods to evaluate the column strength at non-uniform temperatures. Therefore this method was adopted here. The measured temperature profiles obtained from the fire tests were used as was done in the previous studies $[5,9]$. The temperatures of the studs were measured at mid-height and quarter points throughout the fire tests $[10,11]$. Therefore the average values of the measured temperatures were used over the entire stud length using Simplification 1 (Figure 8 (d)). In this model, spatial field was used to create linearly varying temperatures in the web element.

\subsection{Initial Geometric Imperfections}

Light gauge cold-formed steel sections are likely to have larger initial geometric imperfections. Therefore relevant initial geometric imperfection was included in the nonlinear analyses by introducing it to the appropriate buckling mode obtained from the bifurcation buckling analyses of LSF wall stud. Figure 9 shows the first eigen mode representing local web buckling. The local web buckling near the support is predominant in this mode and also in the test results [10]. Therefore this eigen mode was used to introduce the initial geometric imperfection with an appropriate amplitude at ambient temperature.

The effect of initial imperfection amplitude on the ultimate capacity of studs at ambient temperature was investigated using FEA. Table 2 shows the initial imperfection amplitudes used by other researchers $[9,23,24]$ and the ultimate compression capacities. The use of $0.006 \mathrm{~b}$ as the initial local imperfection agreed well with our test results and hence it was adopted in this study.

In the FEA of studs under fire conditions, the lowest eigen buckling mode at ambient temperature was used to input the initial imperfections (Mode 1). Two other modes were also considered. Mode 2 was obtained by analysing the stud with the reduced mechanical properties at the hot flange temperature. Mode 3 was obtained by analysing the stud with varying temperature dependant mechanical properties across the section. However, the nonlinear analyses with these three different eigen buckling modes resulted in the same 
ultimate load. This is because the dominance of thermal bowing did not allow the initial geometric imperfection to have any significant effect on the strength of LSF wall studs subject to non-uniform elevated temperature distributions (Figures 2 and 8).

\subsection{Residual Stresses}

The residual stress is an important parameter influencing the axial compressive strength of steel studs as this can cause premature yielding. The residual stress models proposed in [24] have higher residual stresses at the rounded corners of lipped channel sections. However, the press-braked sections used in this research had sharp corners, and the corner radii were negligibly small. In this case the corner regions with higher residual stresses can be neglected. A new set of residual stresses for lipped channel sections without the rounded corners was proposed in [25]. These values were used in the finite element model at ambient temperature. However, their effect was found to be small $(<0.5 \%)$ in the prediction of their ultimate load capacity. It will be even more insignificant at elevated temperatures. Hence residual stresses were not considered in the modelling of studs under fire conditions. Similar assumption was also used by other researchers $[5,7,9]$.

\section{Finite Element Analyses of LSF Wall Studs under Ambient Conditions}

Two types of analyses, namely, bifurcation buckling and nonlinear analyses, were conducted using ABAQUS [14]. The bifurcation buckling analyses were used to determine the elastic buckling loads and modes. The relevant buckling modes were then used to include the initial geometric imperfections in the nonlinear analyses. Finally the nonlinear analyses using the Riks On method were used to determine the ultimate loads of LSF wall studs.

The results from finite strip analyses and tests [10] were used to validate the results of finite element analyses at ambient temperature. Figure 10 (a) shows a close agreement between the results of elastic buckling load and mode from CUFSM [13] and ABAQUS [14] (39.5 and $39.8 \mathrm{kN}$ ). The ultimate failure loads from the full scale test and ABAQUS [14] also agreed well $(79.0$ and $77.3 \mathrm{kN})$. The studs failed due to local buckling of web and flanges at the base close to the loading point in the test [10]. This was confirmed by ABAQUS [14] as shown in Figure 10 (b). These comparisons show that the developed finite element model accurately predicts the elastic buckling and ultimate capacities and failure modes of studs subjected to axial compression at ambient temperature. 


\section{Finite Element Analyses of LSF Wall Studs under Fire Conditions}

Finite element program ABAQUS [14] was used for both elastic buckling and nonlinear analyses under fire conditions. Finite element analyses of steel members under fire conditions can be conducted under two conditions, namely steady state and transient state conditions. In the steady state modelling, the non-uniform temperature distributions in the steel crosssection are raised to the target levels and then maintained. A load is then applied in increments until failure. In the transient state modelling, the target load is first applied to give a particular load ratio, after which the measured non-uniform temperature distributions in the stud are input in a time frame. In the past, some researchers [7] used steady state modelling while others $[5,9]$ used transient state modelling in their numerical analyses.

Full scale fire tests were undertaken based on transient state conditions. In order to validate the finite element models using fire test results, it is important to simulate the complete loading history as used in the tests. Therefore finite element analyses were performed under transient state conditions. However, to develop suitable fire design rules, the compression capacities of studs are needed for given time-temperature profiles. In this case the analyses were performed under steady state conditions.

\subsection{Finite Element Analyses under Transient State Conditions}

The model creation was similar to that at ambient temperature. The load, support conditions, plasterboard restraints and temperature distributions were applied as boundary conditions. However, the definition of material properties, application of temperature loading and the methods of analysis were different. The analyses were performed in two steps with Riks off method. In the first step the load was increased to the target level and in the second step the measured average time-temperature distributions of the two central studs given in Figure 11 were used based on Simplification 1 (Figure 8). The non-uniform temperature distribution applied to the steel stud simulated the fire from one side of the wall and hence the variation in mechanical and thermal properties of steel at elevated temperatures was included in the analyses. Three LSF walls tested in [11] were considered here (Table 3). The analysis was conducted in a time frame to arrive at a deformation versus time curve for each test. The accuracy of the developed finite element models was verified by using the experimental deformation curves of LSF wall studs under fire conditions. 
Numerical problems were experienced near the test failure time. A range of values from $1.0 \times 10^{-11}$ to $1.0 \times 10^{-9}$ was used as the dissipated energy fraction. The value $1.0 \times 10^{-11}$ was found to be adequate to stabilise the model while having minimal viscous energy dissipated. Similar failure times were obtained with and without the usage of stabilization method. However, the use of a stabilize factor helped to obtain the failure modes and to confirm the failure time in FEA.

\subsubsection{Deflected Stud at Different Time Intervals}

Figure 12 (a) shows the shortened Stud 3 of Test 1 after the axial loading step. Until this point, the stud was not subjected to any temperature loading. Figure 12 (b) shows the stud after 115 minutes of the temperature loading step. At this point, the stud has elongated due to the temperature loading. The thermal bowing towards the fire side can also be observed due to the temperature gradient across the stud.

\subsubsection{Axial Deformation and Lateral Deflection}

Figures 13 and 14 show the axial deformation and lateral deflection versus time curves, respectively, for Tests 1 to 3 . During the fire test, the axial deformation was positive and increased with time due to thermal expansion. However, at failure the stud could no longer carry the applied load and hence its axial deformation decreased. This behaviour was also observed in FEA and the sharp fall in axial deformation indicates that Test 1 Studs 2 and 3 failed after 118 and 115 minutes, respectively.

The FEA results in Figure 14 (a) show that the lateral deflection of Test 1 Stud 2 decreased near the failure while it increased for Stud 3. This is due to the difference in the timetemperature distributions of these studs near failure. Figure 11 (a) shows that the temperature difference between the hot and cold flanges decreased in Stud 2 near failure, however, it increased in Stud 3. Although this difference in lateral deflection can be observed in FEA due to the use of simplified stud models, such isolated behaviour of stud is practically not possible in full scale tests. Regardless of this difference, the overall agreement of FEA and test load-deformation curves is very good. 


\subsubsection{Thermal Bowing and Magnified Thermal Bowing}

Equation 3 gives the mid-height deflection $e_{\Delta T}$ due to thermal bowing of simply supported steel members caused by temperature gradient across the section [26].

$e_{\Delta T}=\frac{\alpha \Delta T L^{2}}{8 d}$

where $\alpha$ is the coefficient of thermal expansion for steel; $L$ is the member length; $\Delta T$ is the temperature difference across the member and $d$ is the member depth.

In the presence of an axial compression load in the LSF wall stud, a bending moment will be generated due to this thermal bowing. This will cause the stud to bend further towards the furnace. This additional horizontal deflection due to P- $\Delta$ effects is called the magnified thermal bowing or the secondary deformation [27].

Figure 15 shows the lateral deflection obtained from the test, FEA and Equation 3 for Stud 2 of Test 1 . It is interesting to note that the lateral deflection predicted by FEA follows the same trend as Equation 3. The difference between these curves is due to the magnified thermal bowing as FEA includes both thermal bowing and P- $\Delta$ effects. The magnified thermal bowing effect is directly proportional to thermal bowing [2,9] as seen in the lateral deflection predicted by FEA.

\subsubsection{Failure Modes and Location}

Figure 16 shows the failure modes obtained from test and FEA for Stud 3 of Test 1 . In the test the stud failed by moving away from the furnace. However, FEA predicted the stud failure towards the furnace. The deformations of the stud and the loading plate due to thermal bowing will induce an eccentric loading towards the hot side. This eccentric loading and the effect of neutral axis shift can cause the stud to reverse its movement. Therefore in the final stage of the test, the stud bent away from the furnace for most of the tests. However, this eccentric loading was not considered in FEA and this resulted in failures towards the furnace due to temperature gradient effects. Same observations were reported in [9]. This is further discussed in this paper using the FEA results obtained under steady state conditions. 


\subsection{5. von Mises Stress}

Figure 17 shows the variation of yield stress and von Mises stress with respect to time for a node close to the support for Stud 3 of Test 1. The reduction in yield stress is very low up to 90 minutes when the temperature of the node is less than $300^{\circ} \mathrm{C}$. However, beyond 90 minutes of fire test, the yield stress deteriorates rapidly due to temperature rise. At the beginning the von Mises stress depends on the stress due to applied loading (load ratio of 0.2). When the increasing temperature distribution was applied the von Mises stress increased gradually until it reached the temperature dependant yield stress. After this, the von Mises stress could not increase beyond the yield stress, and thus followed the path of temperature dependent yield stress. Similar variation of von Mises stress was observed for all the nodes in the web near the support. The von Mises stress reached the yield stress after 95 minutes for the majority of nodes in the web element. After this, it spread to the stronger side of the cross-section (cold flange) and the stud survived another 20 minutes before the hot flange underwent significant yielding at failure.

\subsubsection{Variation of Applied Load}

Figure 18 shows the variation of applied load with time from Test 1 and FEA. The term total time is used here to include both Steps 1 and 2. Step 1 (application of load) is shown in the first minute. The applied load of $15 \mathrm{kN} / \mathrm{stud}$ was maintained in both test and FEA and the increasing temperature distributions were applied in Step 2. The test was stopped after 118 minutes in Test 1 when the stud could no longer sustain the applied load. In FEA the command given was to maintain the applied load while increasing the temperature. However, after 115 minutes ABAQUS [14] could not sustain the load of $15 \mathrm{kN}$ due to severe local buckling observed at the support at high temperatures. This confirms the failure of the stud and the failure time was recorded as 115 minutes in FEA. The failure times of Test 2 and 3 were determined similarly.

\subsubsection{Discussion of Results}

The accuracy of the developed finite element models was verified by using the deformationtime curves, failure modes and failure times (ie. also FRR) of LSF wall panels from the fire tests of this research [11]. Table 3 shows that the failure times obtained from FEA agreed well with test failure times. 
Finite element analyses of LSF walls under transient state conditions were also reported in [9]. In comparison to the results in [9], the comparison of failure time and deformation-time curves from tests and FEA is very good. One of the possible reasons for this is the use of accurate reduction factors based on measured mechanical properties of Australian coldformed steels at elevated temperatures [20]. Another reason could be the correct assumption of temperature profiles. In this study the average measured temperatures of the stud along its length were considered.

\subsection{Finite Element Analysis under Steady State Conditions}

Finite element analyses were also conducted under steady state conditions. It is convenient to compare the results in this case with design calculations. The stud with the vertical plasterboard joint against it experienced higher temperatures than other studs in the wall panel. Therefore this stud failed before other studs during fire tests. In the FEA under transient conditions both central studs were modelled and it was proved that the stud with the vertical plasterboard joint failed earlier. Therefore the critical stud with the vertical plasterboard joint was considered in the finite element analyses under steady state conditions. The temperature profiles were based on the average and mid-height time-temperature distributions for the critical stud as obtained from fire tests.

The nonlinear finite element analyses of the stud under steady state conditions were performed using two steps at close time intervals from the start of fire test. Figure 11 gives the average and mid-height time-temperature distributions in the critical central stud for the LSF wall configurations as used in Tests 1 to 3 . In the first step, time-temperatures profiles at the chosen time were taken from Figure 11 and applied to the stud, and in the second step the load was applied and increased until failure. The Riks off method and the Riks on method were used for the first and second steps, respectively. The Riks on method was used in the loading (second) step to determine the ultimate load, which is different to the transient state analyses. In the transient state analyses Riks off method was used for the loading step to achieve the target load (not the ultimate load).

Many analyses conducted in close time intervals led to a load ratio (ultimate load of stud in fire conditions / ambient temperature capacity) versus failure time (FRR) curve for the LSF wall systems used in Tests 1 to 3. Figure 19 (a) shows this curve for the case of LSF wall with glass fibre external insulation while Figure 19 (b) shows the variation of load ratio with 
respect to the hot flange temperature at failure. As shown in these figures, the failure time and the critical hot flange temperature for Test 1 with a load ratio of 0.2 were obtained as 115 mins. and $600^{\circ} \mathrm{C}$. The main advantage of FEA with steady state conditions is that the figures such as Figure 19 can now be used to obtain the fire resistance rating (failure time) for any given load ratio. Table 4 gives the failure times predicted by FEA under steady state conditions for Tests 1 to 3 .

\subsubsection{Failure Mode and Location}

When non-uniform temperature distributions are applied to the stud cross-section in FEA, a mid-height bending moment will be developed due to the net effect of thermal bowing and neutral axis shift. Hence the cold flange at mid-height will be subjected to compressive stresses due to both axial compression and bending actions. On the other hand at the support the bending moment is only due to the neutral axis shift causing tensile stress on the cold flange. Therefore the cold flange at mid-height is likely to fail than that at the support.

On the other hand the hot flange at mid-height will be subjected to compressive stress due to applied load and tensile stress due to bending action while the hot flange at the support will be subjected to compressive stresses due to both axial compression and bending actions. This indicates that the hot flange is likely to fail near the support than at mid-height.

It is noted that the yield stress of steel reduces with time and hence the strength of cold flange is higher than that of hot flange. Therefore the failure locations of LSF studs can be either in the mid-height cold flange or the support hot flange. This depends on the induced stresses and the yield strength of steel at non-uniform elevated temperatures near the failure time.

Figure 20 shows the failure modes of Stud 3 in Test 1 from FEA under steady state conditions at different times. The failure location for Stud 3 of Test 1 changes from the midheight cold flange to the support hot flange when temperatures increase. Initially at higher load ratios the stud can only withstand lower temperatures. However, due to non-uniform elevated temperatures, the stud will act as a column with initial geometric imperfection about the major axis due to thermal bowing. In this case the stud failure will be initiated by the global imperfection and hence the failure occurred at the mid-height cold flange. Here the temperature gradient and corresponding thermal bowing plays a major role in initiating the 
failure. Figure 21 shows the failure of critical studs at mid-height (cold-flange) from FEA for Tests 2 and 3 where the studs are subject to higher load ratios (0.4).

At lower load ratios the stud can withstand higher temperatures and hence the yield stress of hot flange will reduce considerably, which outplays the effect of thermal bowing due to nonuniform temperature distribution. In this case the failure was at the support hot flange (Figure 20). However, when the cold flange temperature is as high as hot flange temperature, then the failure can be at mid-height cold flange at lower load ratios (Figure 23 (f)).

During the fire tests the mid-height stud temperatures were higher than the support temperatures since the studs were closer to the furnace at mid-height due to thermal bowing. Hence the hot flange becomes more critical at mid-height compared to the hot flange at the support in the tests. Therefore in most of the tests, the stud failed due to the local buckling of hot flange at mid-height that led to rapid movement away from the furnace. However, in FEA, this effect was not considered. Hence as explained earlier the support hot flange is more critical than that at mid-height, leading to stud failure due to local buckling of hot flange at the support, while deforming towards the hot side due to thermal bowing.

\subsubsection{Simulation of Fire Tests from Kolarkar [10]}

Previous sections described the finite element analyses of LSF wall studs under both steady and transient state conditions. Since both these analyses provided similar failure times and hot flange temperatures (Tables 3 and 4), one of them can be used to simulate the behaviour of the remaining seven LSF wall panels in Table 1 [10]. Finite element analyses under steady state conditions provide an additional output in the form of load ratio versus time for the wall configurations considered in the tests. Therefore FEA were conducted under steady state conditions using both the average and the mid-height time-temperature distributions of the critical stud with plasterboard joint as obtained from the fire tests (Figure 22). It was observed that the type of insulation used in the cavity of load-bearing walls has a low influence on the stud temperatures. On the other hand the hot flange temperatures of externally insulated load-bearing walls are influenced by the type of insulation used.

\subsubsection{Discussion of Results}

Figure 23 compares the failure modes obtained from FEA with those from Tests $1^{*}$ to $7^{*}$. Since the load ratio is 0.2 in these tests, FEA predicts the failure to be mostly near the support 
as explained in Section 5.2.1. However, in Test $6 *$ the cold flange temperature was almost as high as the hot flange temperature, and hence the failure was in the mid-height cold flange.

Figures 24 and 25 show the variation of load ratios with time using the average and midheight time-temperature distributions, respectively. As expected, the load ratio did not reduce much for the first few minutes. This is when the plasterboard was dehydrated and hence the stud was protected from fire and the maximum temperature in the stud was less than $100^{\circ} \mathrm{C}$. Following this the load ratio reduced rapidly with time due to two reasons. First reason was the increasing temperature of stud with time, which leads to lower ultimate capacity due to reduced mechanical properties. Second reason was the thermal bowing and associated bending moment.

Near the failure time the lateral restraint provided by the plasterboards was taken into account in FEA because the base layer of the fire side plasterboard maintained its integrity until failure. However, some parts of the fire side face layer plasterboards fell off and this resulted in a rapid temperature rise in the stud. This led to a rapid fall in load ratio as observed in the load ratio versus time curve in Figure 24. Hence the predicted failure times for load ratios of 0.2 and 0.4 were closer in most of the tests.

There is a small variation in load ratio versus time graphs when using the average and midheight stud time-temperature distributions due to the slight variation between them. The midheight stud temperature was more than the average stud temperature for most of the tests. Therefore at any given time the load ratio obtained based on mid-height stud temperatures was less than or equal to that obtained based on average stud temperatures.

Figure 26 shows the variation of load ratios with respect to the hot flange temperatures at failure. The load ratio versus hot flange temperature curves for different tests merged well. For a given load ratio, the stud failure temperatures for all the specimens are reasonably close. This means that structurally similar studs will fail at the same critical failure temperature regardless of the number plasterboards and insulation characteristics. The effect of plasterboards and different types of insulation is simply to delay the time to reach this critical temperature in studs. 
A small reduction in load ratio was observed even at lower temperatures of $100-300^{\circ} \mathrm{C}$, where there is not a reduction in yield stress. There are two reasons for this. First the elastic modulus has decreased even at these low temperatures. Secondly, even in this initial phase, the stud experienced some temperature differences across the stud. This results in lateral deflections and hence bending moment due to eccentricity in the stud. These effects caused the reduction in load ratios even at temperatures below $300^{\circ} \mathrm{C}$.

The accuracy of the developed finite element models was investigated by comparing the failure times of LSF wall studs from FEA and test. In FEA the failure time was obtained by finding the time at a given load ratio using the load ratio curve obtained from FEA. In FEA most of the tests with a load ratio of 0.2 failed when the hot flange temperature was nearly $600^{\circ} \mathrm{C}$ or above. The specimens under a load ratio of 0.4 failed at about $500^{\circ} \mathrm{C}$ or above. This shows that the current limiting temperature of $350^{\circ} \mathrm{C}$ based on [22] is too conservative.

Table 4 compares the predicted FEA failure times under steady state conditions with those obtained from the fire tests. When mid-height temperatures were used, conservative results were obtained with a maximum deviation of $10 \%$. However, the FEA results agreed well with test results when average temperatures of the stud were used. Except Test $6^{*}$, the difference between the failure times from FEA and tests does not exceed 5\% (within 5 minutes), which is a considerable improvement. The superior fire performance of externally insulated panels over that of cavity insulated panels observed in fire tests $[10,11]$ was confirmed by FEA results in Table 4, in particular for rock fibre insulated walls. Glass fibre insulation is not recommended in LSF wall panels when it is subjected to lower load ratios. In this case the studs can withstand higher temperatures at which the glass fibre melts and becomes ineffective.

\section{Conclusions}

This paper has described the finite element models developed to simulate the behaviour of load bearing LSF wall panels subject to standard fire conditions on one side. Finite element analyses under transient and steady state conditions agreed well with the results from 10 full scale fire tests. The use of accurate finite element models as described in this paper allowed the inclusion of various complex thermal and structural effects such as thermal bowing, local buckling and neutral axis shift of LSF wall studs subject to non-uniform elevated temperature distributions during fires. Finite element analysis results confirmed the superior fire 
performance of externally insulated LSF walls in comparison to cavity insulated walls. They provided very useful load ratio versus time curves for many LSF wall configurations used in the fire tests. These curves can be used to predict the fire resistance rating of LSF walls with similar plasterboard and insulation configurations subject to other load ratios without further testing or analyses. The results also included load ratio versus hot flange temperature at failure, which merged reasonably well. This means that structurally similar studs will fail at the same hot flange temperature regardless of the number of plasterboards and types of insulation. The effect of plasterboards and types of insulation is simply to delay the time to reach that critical temperature in the steel stud. The LSF wall panels considered here failed at about $600^{\circ} \mathrm{C}$ and $500^{\circ} \mathrm{C}$ for the load ratios of 0.2 and 0.4 , respectively. This shows that the current limiting temperature method of using $350^{\circ} \mathrm{C}$ [22] for cold-formed steel structures is too conservative.

\section{Acknowledgements}

The authors would like to thank Australian Research Council for their financial support and the Queensland University of Technology for providing the necessary facilities and support to conduct this research project.

\section{References}

[1] Klippstein, K.H. (1980), Strength of Cold-Formed Studs Exposed to Fire, American Iron and Steel Institute. Washington, DC.

[2] Gerlich, J.T., Collier, P.C.R. and Buchanan, A.H. (1996), Design of Steel-framed Walls for Fire Resistance, Fire and Materials, Vol.20, No.2, pp.79-96.

[3] Kodur, V.R. and Sultan, M.A. (2001), Factors governing fire resistance of load-bearing steel stud walls, Proceeding of the Fifth AOSFST International Conference, Newcastle, Australia, pp.1-2.

[4] Alfawakhiri, F. (2001), Behaviour of Cold-formed-Steel-framed Walls and Floors in Standard Fire Resistance Tests, PhD Thesis. Carlton University, Ottawa, Ontario, Canada. 
[5] Kaitila, O. (2002), Finite Element Modelling of Cold-formed Steel Members at High Temperatures, Licentiate Thesis, Helsinki University of Technology, Espoo, Finland.

[6] Feng, M., Wang, Y.C. and Davies, J. M. (2003a), Thermal Performance of Cold-formed Thin-walled Steel Panel Systems in Fire, Fire Safety Journal, Vol.38, pp.365-394.

[7] Feng, M., Wang, Y.C. and Davies, J.M. (2003b), Axial Strength of Cold-formed ThinWalled Steel Channels under Non-uniform Temperatures in Fire, Fire Safety Journal, Vol.38, pp.679-707.

[8] Feng, M. and Wang, Y.C. (2005), An Experimental Study of Loaded Full-Scale ColdFormed Thin-Walled Steel Structural Panels Under Fire Conditions, Fire Safety Journal, Vol.40, pp. 43-63.

[9] Zhao, B., Kruppa, J., Renaud, C., O’Connor, M., Mecozzi, E., Apiazu,. W., Demarco, T., Karlstrom, P., Jumppanen, U., Kaitila, O., Oksanen, T. and Salmi, P. (2005), Calculation Rules of Lightweight Steel Sections in Fire Situations, Technical Steel Research, European Union, France.

[10] Kolarkar, P.N. (2010), Fire Performance of Plasterboard Lined Steel Stud Walls, PhD Thesis, Queensland University of Technology, Brisbane, Australia.

[11] Gunalan, S. (2011), Structural Behaviour and Design of Cold-formed Steel Wall Systems under Fire Conditions, PhD Thesis, Queensland University of Technology, Brisbane, Australia.

[12] Standards Australia (2005), AS 1530.4 Methods for Fire Tests on Building Materials, Components and Structures, Part 4: Fire-resistance Tests of Elements of Building Construction, Sydney, Australia.

[13] Li, Z. and Schafer, B.W. (2010), Buckling Analysis of Cold-formed Steel Members with General Boundary Conditions using CUFSM: Conventional and Constrained Finite Strip Methods, Proceedings of the 20th International Speciality Conference on Cold-Formed Steel Structures, St. Louis, MO, USA. 
[14] Hibbitt, Karlsson and Sorensen, Inc. (HKS) (2009), ABAQUS User's Manual, New York, USA.

[15] Telue, Y. and Mahendran, M. (2004), Behaviour and Design of Cold-formed Steel Wall Frames Lined with Plasterboard on Both Sides, Engineering Structures, Vol.26, pp. 567-579.

[16] Luiz, C.M., Vieira, Jr. and Schafer, B.W. (2012), Lateral Stiffness and Strength of Sheathing Braced Cold-formed Steel Stud Walls, Engineering Structures, Vol.37, pp. 205-213.

[17] Avery, P. and Mahendran, M. (2000), Distributed Plasticity Analysis of Steel Frame Structures Comprising Non-compact Sections, Engineering Structures, Vol.22, pp. 901919.

[18] Mahaarachchi, D. and Mahendran, M. (2004), Finite Element Analysis and Design of Crest-fixed Trapezoidal Steel Claddings with Wide Pans Subject to Pull-through Failures, Engineering Structures, Vol.26, pp. 1547-1559.

[19] Gunalan, S., Kolarkar, P.N. and Mahendran, M. (2013), Experimental Study of Load Bearing Cold-formed Steel Wall Systems under Fire Conditions, Thin-Walled Structures, Vol. 64, pp.72-92.

[20] Dolamune Kankanamge, N. and Mahendran, M. (2011), Mechanical Properties of Coldformed Steels at Elevated Temperatures, Thin-Walled Structures, Vol.49, pp. 26-44.

[21] Ranawaka, T. and Mahendran, M. (2009), Experimental Study of the Mechanical Properties of Light Gauge Cold-formed Steels at Elevated Temperatures, Fire Safety Journal, Vol.44, pp. 219-229.

[22] EN 1993-1-2 (2005), Eurocode 3: Design of steel structures. Part 1-2: General Rules Structural Fire Design, European Committee for Standardization, Brussels. 
[23] Standards Australia (1998), Steel structures, AS 4100, Sydney, Australia.

[24] Schafer, B.W. and Pekoz, T. (1998), Computational Modelling of Cold-formed Steel: Characterizing Geometric Imperfections and Residual Stresses, Journal of Constructional Steel Research, Vol.47, pp. 193-210.

[25] Ranawaka, T. and Mahendran, M. (2010), Numerical Modelling of Light Gauge Coldformed Steel Compression Members Subjected to Distortional Buckling at Elevated Temperatures, Thin-Walled Structures, Vol.48, pp. 334-344.

[26] Cooke, G.M.E. (1987), Thermal Bowing and How It Affects the Design of Fire Separating Construction, Fire Research Station, Building Research Establishment, UK.

[27] Alfawakhiri, F., Sultan, M.A. and MacKinnon, D.H. (1999), Fire Resistance of Loadbearing Steel-stud Walls Protected with Gypsum Board: A review, Fire Technology, Vol.35 (4), pp. 308-335. 
Table 1: Details of Tested LSF Wall Specimens

\begin{tabular}{|c|c|c|c|c|c|}
\hline Test & Configuration & Insulation & $\begin{array}{l}\text { Load } \\
\text { Ratio }\end{array}$ & $\begin{array}{c}\text { Test Failure } \\
\text { Time (FRR) } \\
\text { (min.) }\end{array}$ & $\begin{array}{c}\text { Vertical } \\
\text { Plasterboard } \\
\text { Joints }\end{array}$ \\
\hline 1 & 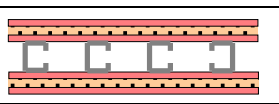 & $\begin{array}{l}\text { Glass } \\
\text { Fibre }\end{array}$ & 0.2 & 118 & Studs 1 and 3 \\
\hline 2 & 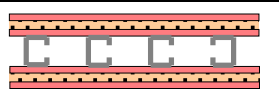 & $\begin{array}{l}\text { Glass } \\
\text { Fibre }\end{array}$ & 0.4 & 108 & Studs 1 and 3 \\
\hline 3 & 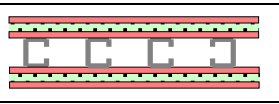 & $\begin{array}{l}\text { Rock } \\
\text { Fibre }\end{array}$ & 0.4 & 134 & Studs 2 and 4 \\
\hline $1 *$ & ए & None & 0.2 & 53 & Studs 2 and 4 \\
\hline $2 *$ & 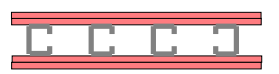 & None & 0.2 & 111 & Studs 2 and 4 \\
\hline $3 *$ & 1atale & $\begin{array}{l}\text { Glass } \\
\text { Fibre }\end{array}$ & 0.2 & 101 & Studs 2 and 4 \\
\hline $4 *$ & $A \because \cdots$ & $\begin{array}{l}\text { Rock } \\
\text { Fibre }\end{array}$ & 0.2 & 107 & Studs 2 and 4 \\
\hline $5 *$ & a & $\begin{array}{l}\text { Cellulose } \\
\text { Fibre }\end{array}$ & 0.2 & 110 & Studs 1 and 3 \\
\hline $6 *$ & 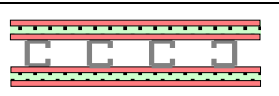 & $\begin{array}{l}\text { Rock } \\
\text { Fibre }\end{array}$ & 0.2 & $136^{\#}$ & Studs 2 and 4 \\
\hline $7 *$ & 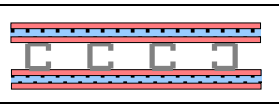 & $\begin{array}{l}\text { Cellulose } \\
\text { Fibre }\end{array}$ & 0.2 & 124 & Studs 2 and 4 \\
\hline
\end{tabular}

( 1 - 3 ) - Fire Tests conducted by Gunalan [11]

$\left(1^{*}-7^{*}\right)$ - Fire Tests conducted by Kolarkar [10]

(\#) - Earlier failure due to lack of space for thermal expansion

Table 2: Effect of Initial Imperfection Amplitude on the Ultimate Load

\begin{tabular}{|c|c|c|c|c|c|}
\hline $\begin{array}{c}\text { Imperfection } \\
\text { Amplitude }\end{array}$ & $\begin{array}{c}0.006 \mathrm{~b} \\
(0.533 \mathrm{~mm}) \\
{[24]}\end{array}$ & $\begin{array}{c}\mathrm{b} / 150 \\
(0.592 \mathrm{~mm}) \\
{[23]}\end{array}$ & $\begin{array}{c}6 \mathrm{te}^{-2 \mathrm{t}} \\
(0.692 \mathrm{~mm}) \\
{[24]}\end{array}$ & $\begin{array}{c}1 \mathrm{~mm} \\
{[9]}\end{array}$ & $\begin{array}{c}\mathrm{t} \\
(1.15 \mathrm{~mm})\end{array}$ \\
\hline $\begin{array}{c}\text { Ultimate Load } \\
(\mathrm{kN})\end{array}$ & 77.3 & 77.1 & 76.7 & 75.4 & 74.7 \\
\hline \% Difference* & 2.2 & 2.4 & 2.9 & 4.6 & 5.4 \\
\hline
\end{tabular}

* Comparison with Test Results 
Table 3: Failure Times Predicted by FEA under Transient State Conditions

\begin{tabular}{|c|c|c|c|}
\hline \multirow{2}{*}{ Test } & \multicolumn{3}{|c|}{ Failure Time (min.) } \\
\cline { 3 - 4 } & \multirow{2}{*}{ Test } & \multicolumn{2}{|c|}{ FEA } \\
\cline { 3 - 4 } & & Stud 2 & Stud 3 \\
\hline 1 & 118 & 118 & 115 \\
\hline 2 & 108 & 113 & 111 \\
\hline 3 & 134 & 133 & 136 \\
\hline
\end{tabular}

Table 4: Failure Times Predicted by FEA under Steady State Conditions

\begin{tabular}{|c|c|c|c|c|c|}
\hline \multirow{2}{*}{ Test } & \multicolumn{2}{|c|}{ Failure Time (min.) } & \multicolumn{2}{c|}{$\begin{array}{c}\text { Failure } \\
\text { Temperature }\left({ }^{\circ} \mathrm{C}\right)\end{array}$} \\
\cline { 2 - 6 } & \multirow{2}{*}{ Test } & \multicolumn{2}{|c}{ FEA } & \multicolumn{2}{c|}{ FEA } \\
\cline { 3 - 6 } & & Avg. & Mid.Ht. & Avg. & Mid.Ht. \\
\hline 1 & 118 & 115 & 115 & 602 & 597 \\
\hline 2 & 108 & 110 & 107 & 505 & 520 \\
\hline 3 & 134 & 131 & 131 & 519 & 517 \\
\hline $1^{*}$ & 53 & 53 & 52 & 593 & 598 \\
\hline $2^{*}$ & 111 & 115 & 110 & 606 & 613 \\
\hline $3^{*}$ & 101 & 100 & 90 & 631 & 624 \\
\hline $4^{*}$ & 107 & 105 & 99 & 633 & 633 \\
\hline $5^{*}$ & 110 & 109 & 104 & 632 & 639 \\
\hline $6^{*}$ & $136^{\#}$ & 154 & 153 & 606 & 618 \\
\hline $7^{*}$ & 124 & 129 & 123 & 604 & 603 \\
\hline
\end{tabular}

( 1 - 3 ) - Fire Tests conducted by Gunalan [11]

$(1 *-7 *)$ - Fire Tests conducted by Kolarkar [10]

(\#) - Earlier failure due to lack of space for thermal expansion

FEA - Finite Element Analysis

Avg. - Average

Mid.Ht. - Mid-height 


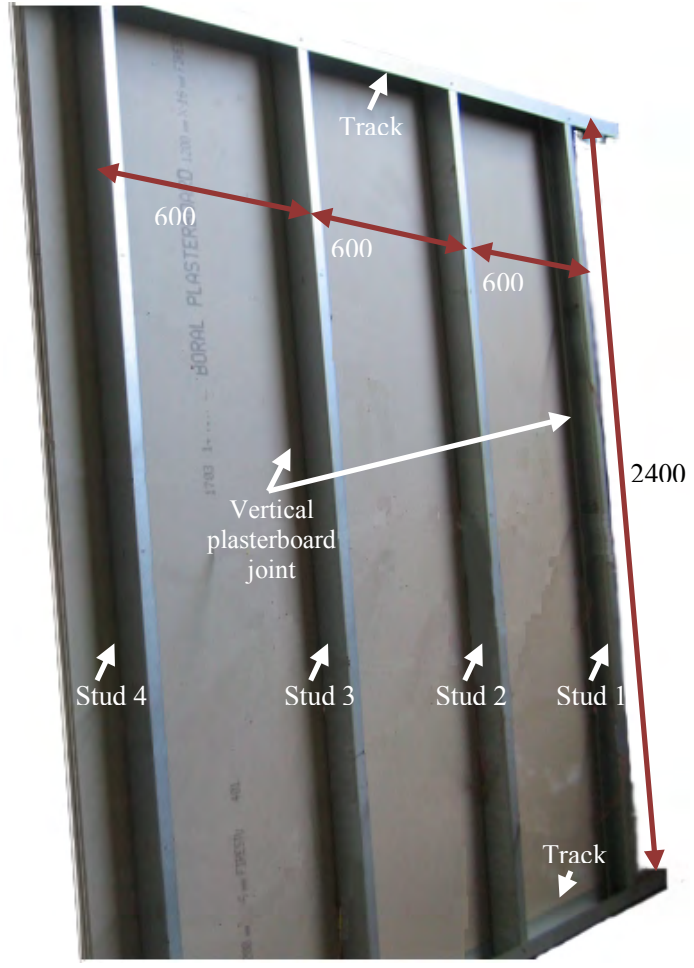

(a) Details of LSF Wall Specimen

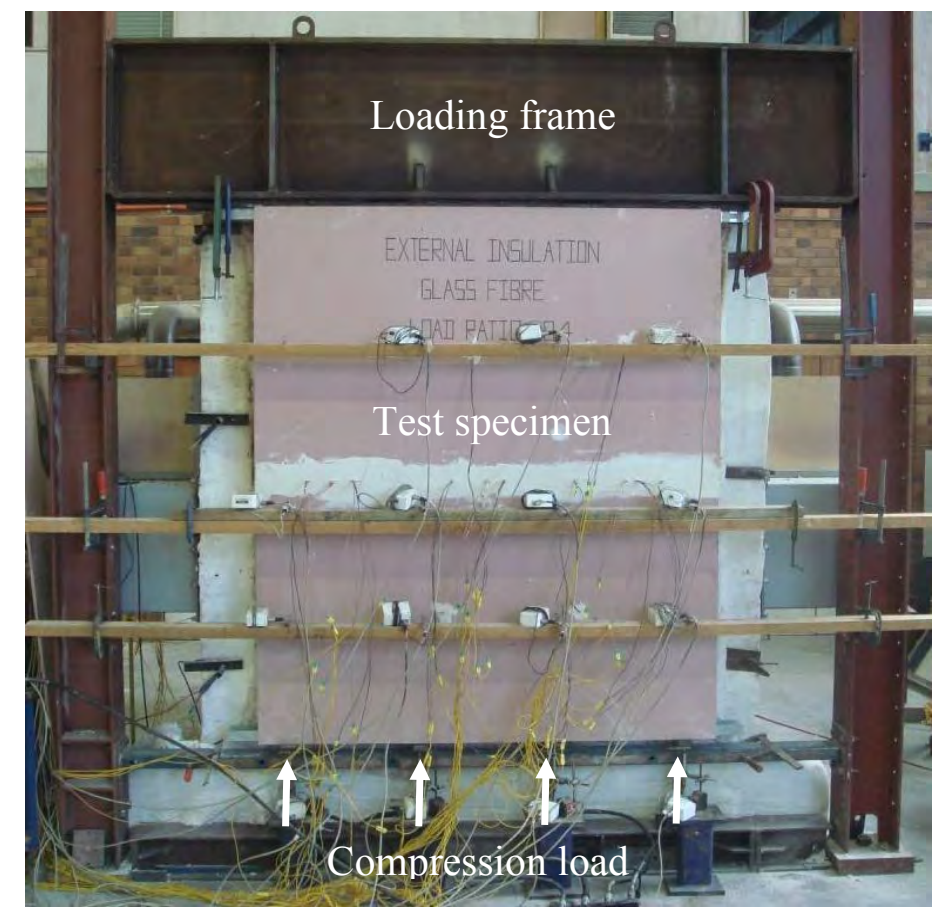

(b) Test Specimen before Fire Test

Figure 1: LSF Wall 


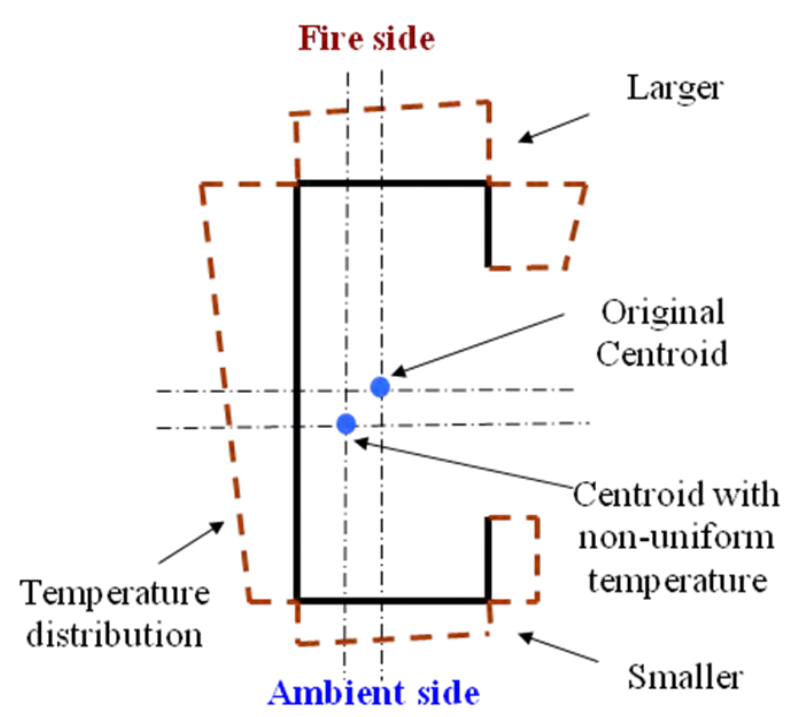

(a) Non-uniform Temperature Distribution

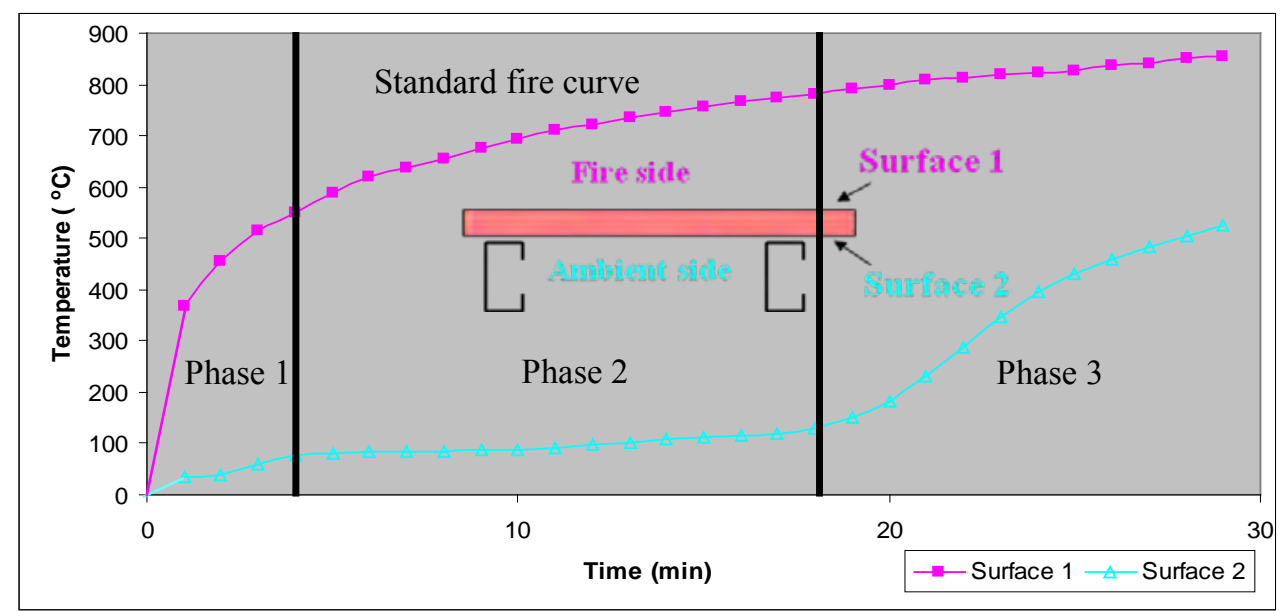

(b) Plasterboard performance

Figure 2: Fire Behaviour of LSF Wall 


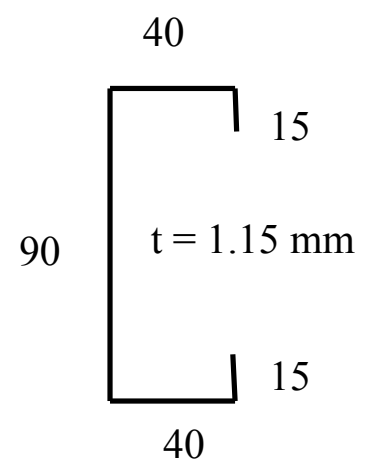
(a) Dimensions

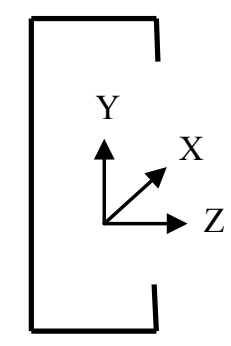

(b) Case 1
Lateral movement (UZ) is restrained

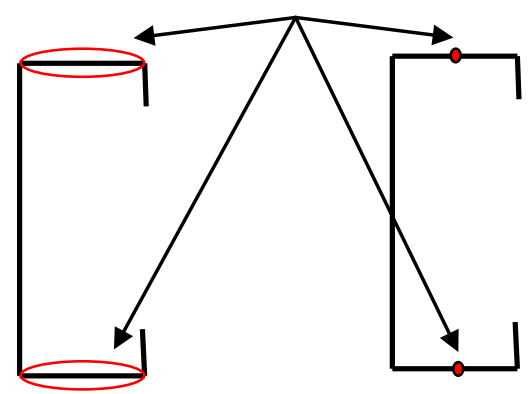

(c) Case 2

(d) Case 3

Figure 3: Cross-sectional Dimensions and Boundary Conditions of the LSF Wall Stud Used in CUFSM Analyses

(a) Load versus

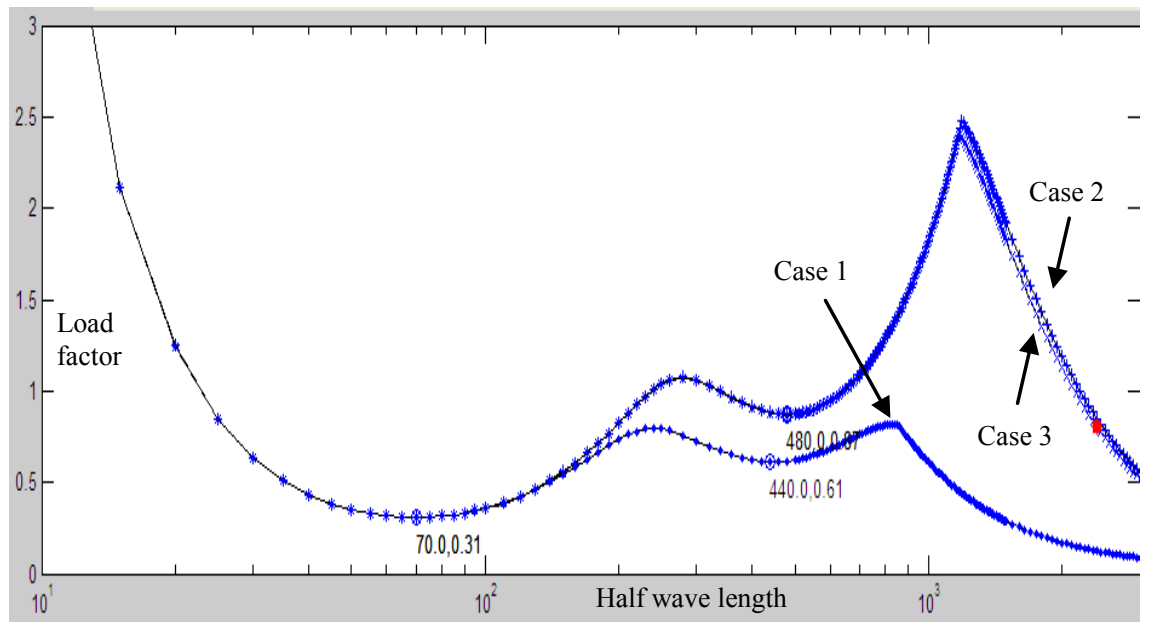

length (HWL) factor (LF) half-wave

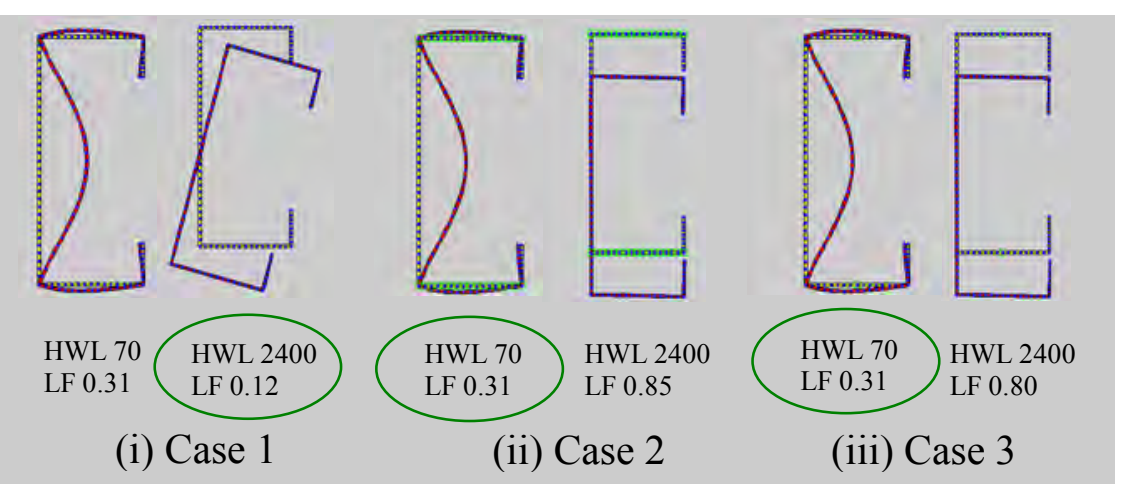

(b) Buckling modes of studs at different half-wave lengths

Figure 4: Results from Finite Strip Analyses 


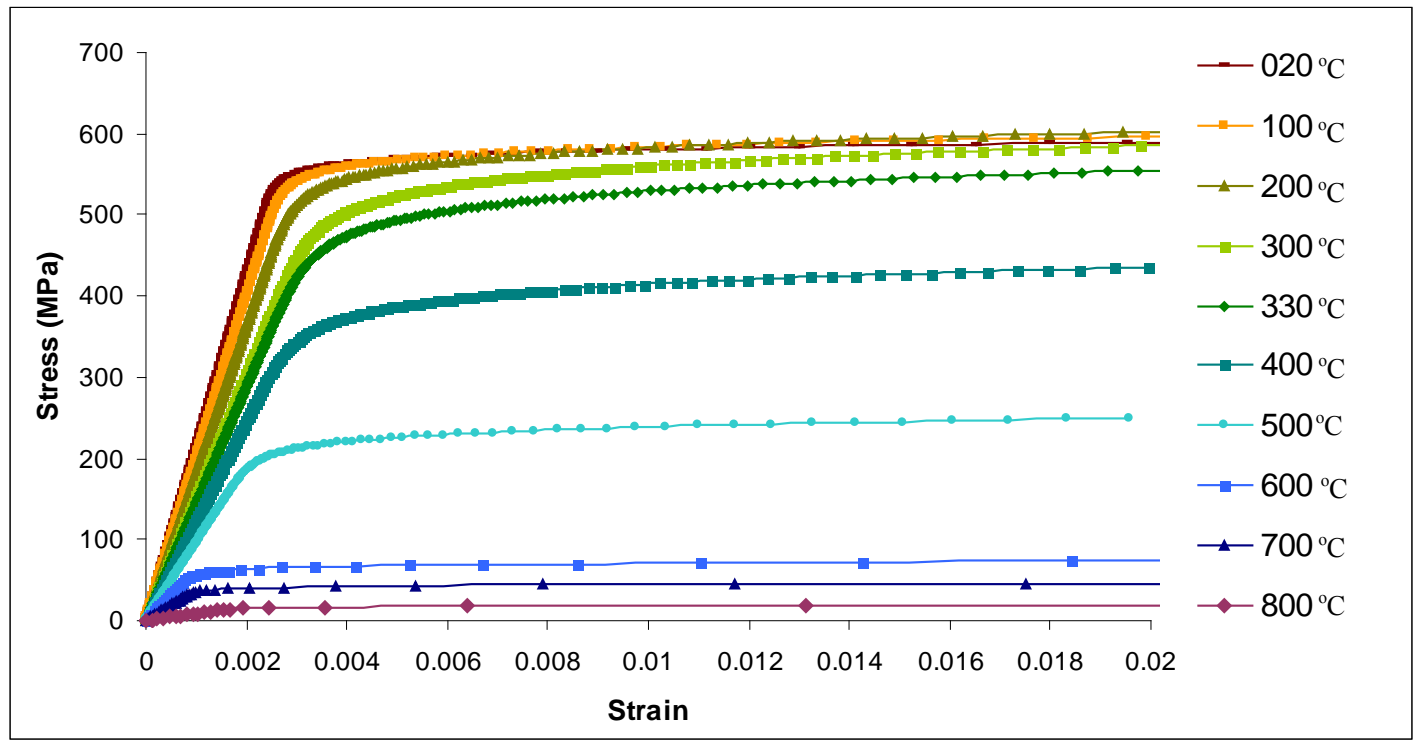

Figure 5: Stress - Strain Curves used in FEA for G500 Steels at Different Temperatures [20] 


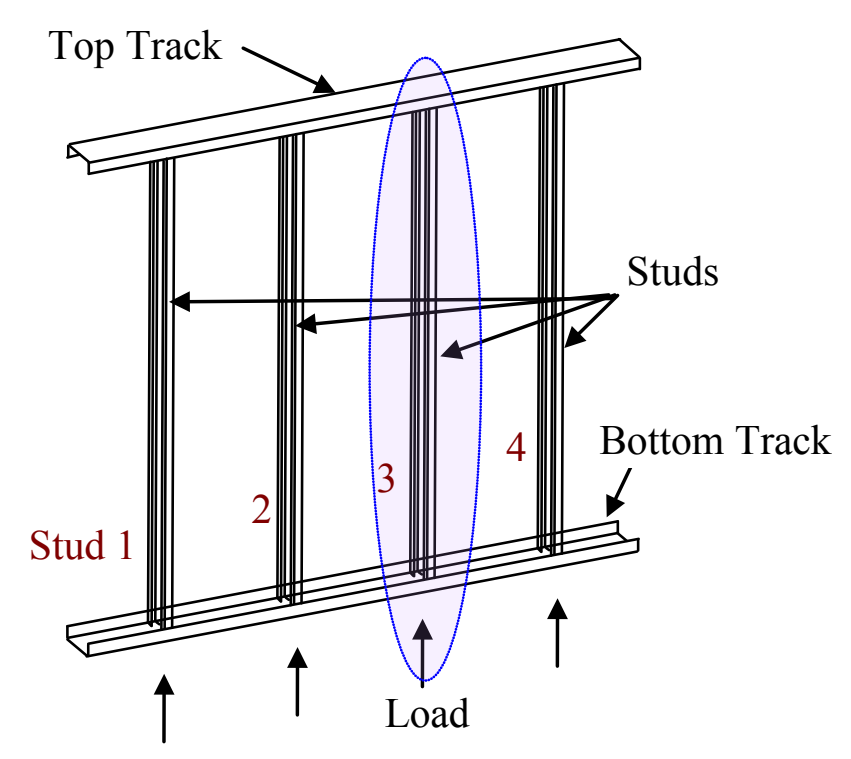

(a) Steel Frame
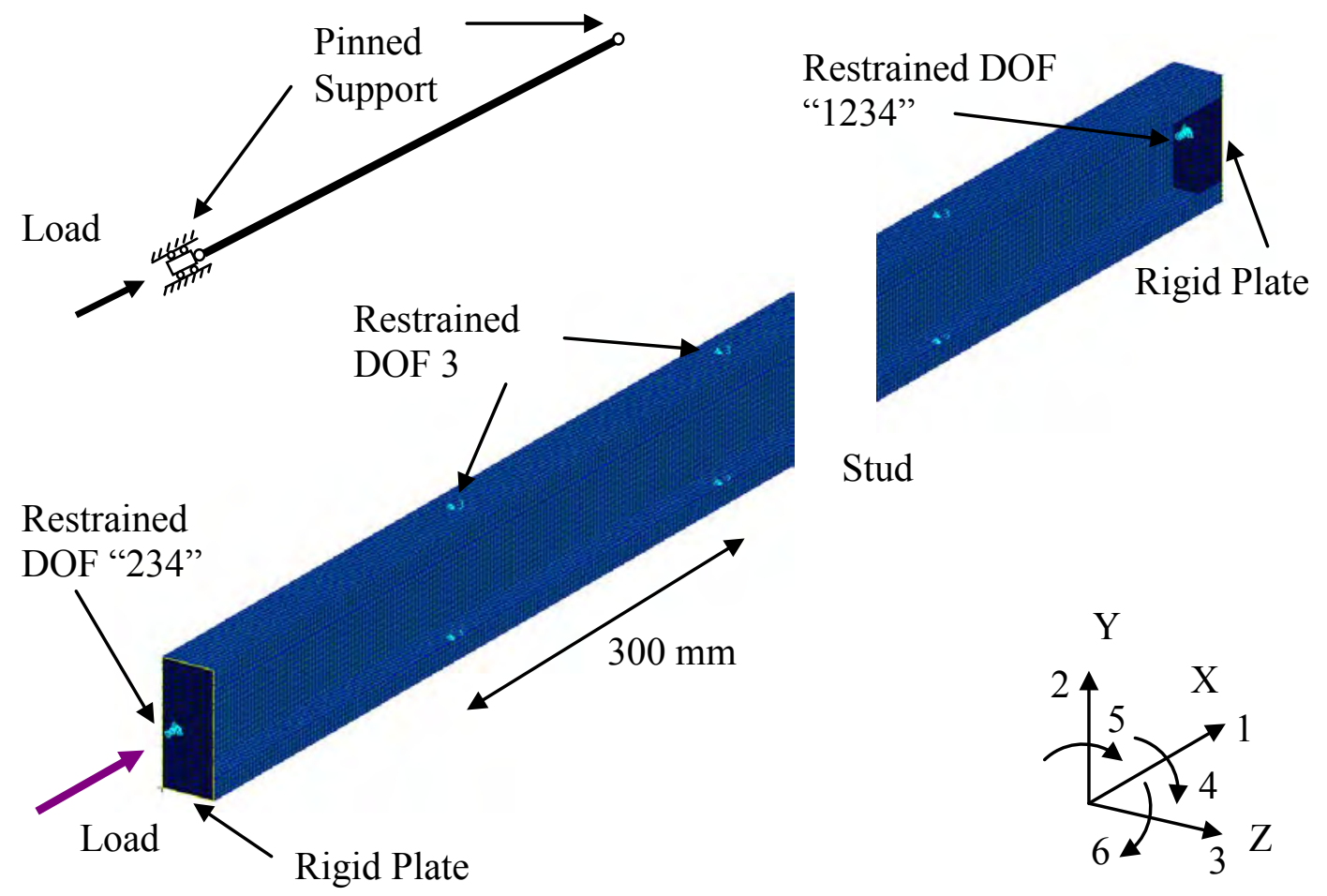

(b) Stud

Figure 6: Loading and Boundary Conditions Used in FEA 


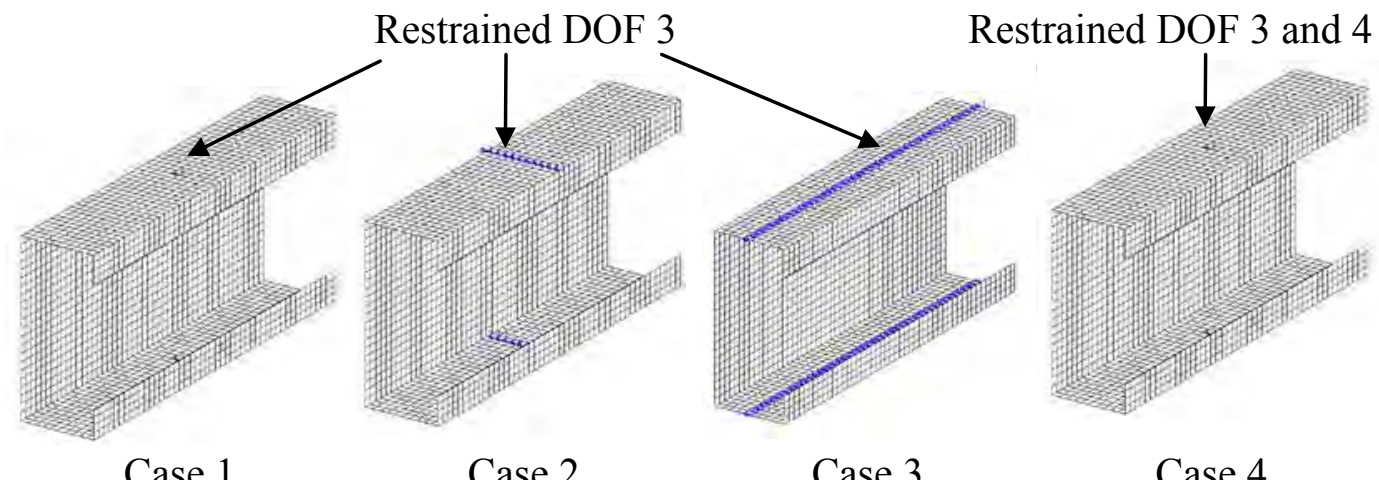

Figure 7: Simulation of Plasterboard Restraints

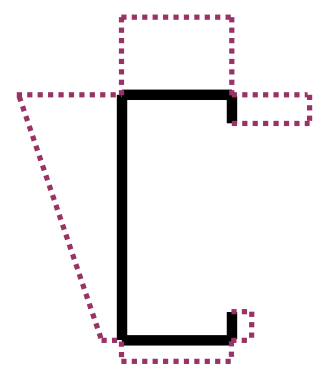

(a) Simplification 1 [7]

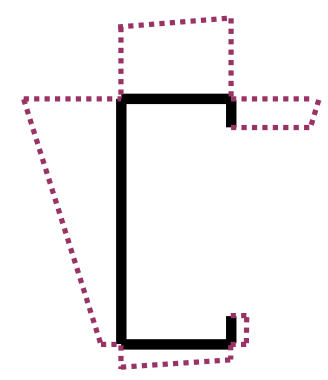

(b) Simplification 2 [7]

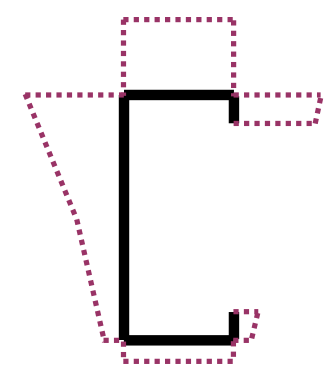

(c) Simplification 3 [9]
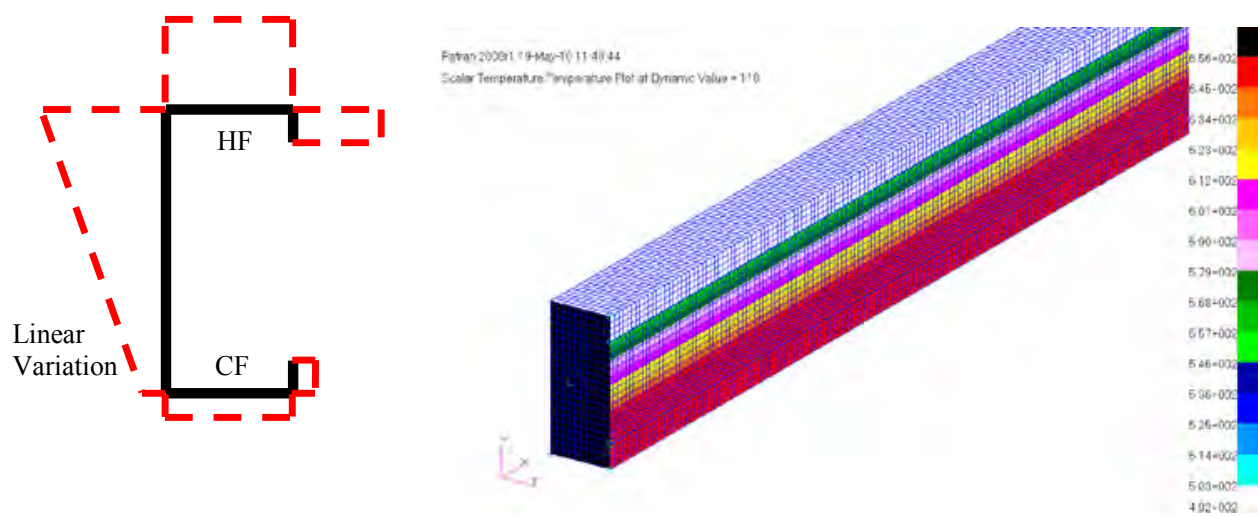

(d) Assumed in the current FEA 

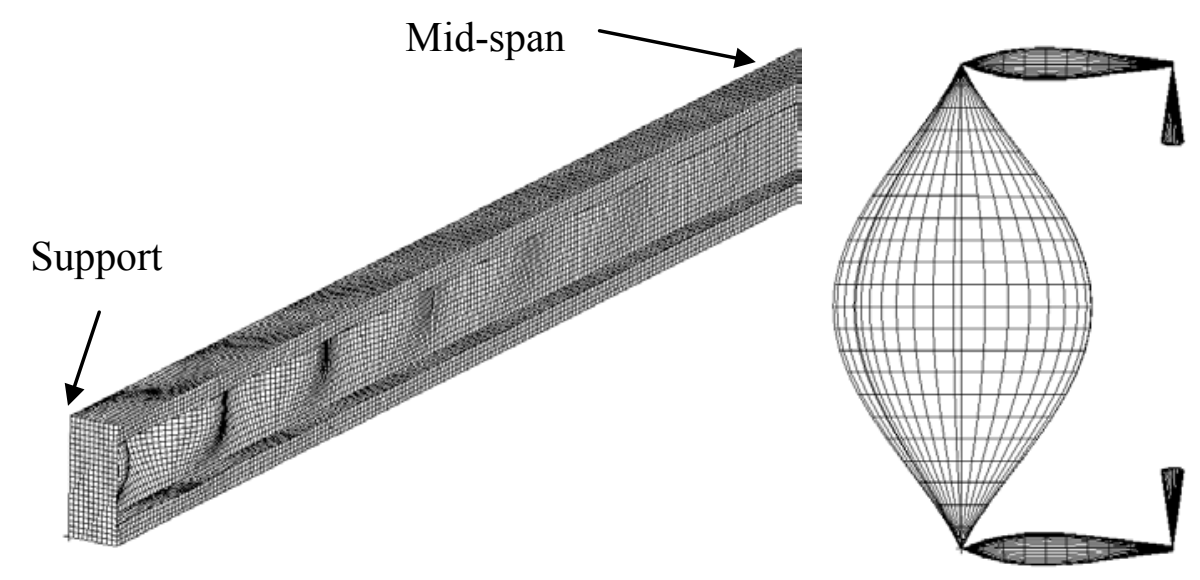

Figure 9: First Eigen Mode from Bifurcation Buckling Analysis

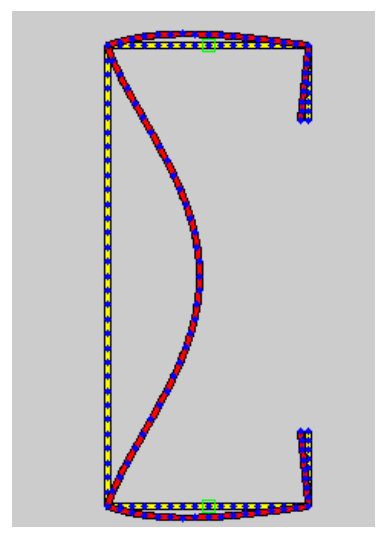

CUFSM

Elastic buckling load $39.5 \mathrm{kN}$

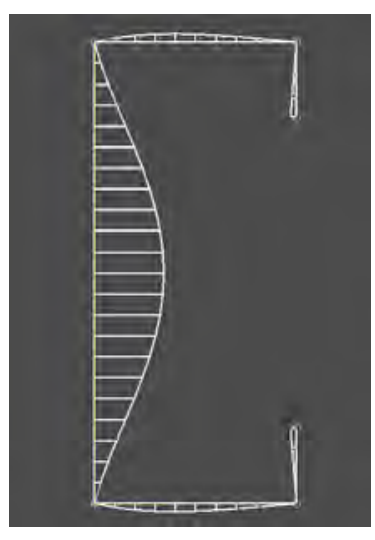

ABAQUS

Elastic buckling load $39.8 \mathrm{kN}$

(a) Elastic Buckling Modes Obtained from Finite Strip (CUFSM) and Finite Element Analyses (ABAQUS)

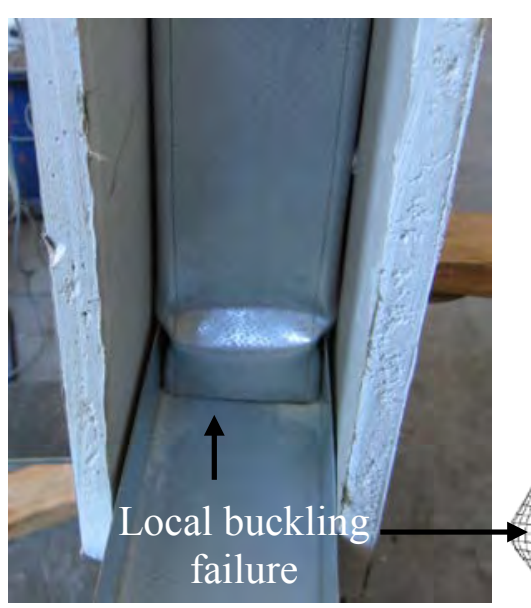

Test

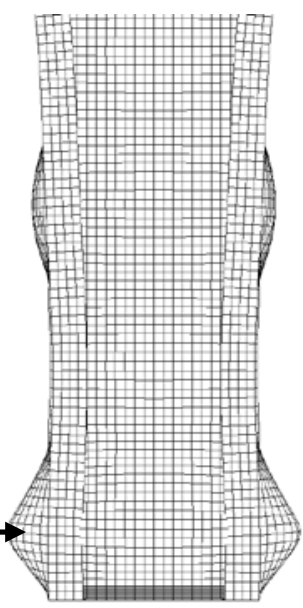

ABAQUS

(b) Failure Modes from Test and Nonlinear Finite Element Analyses (ABAQUS)

Figure 10: Elastic Buckling and Failure Modes 
(a) Test 1

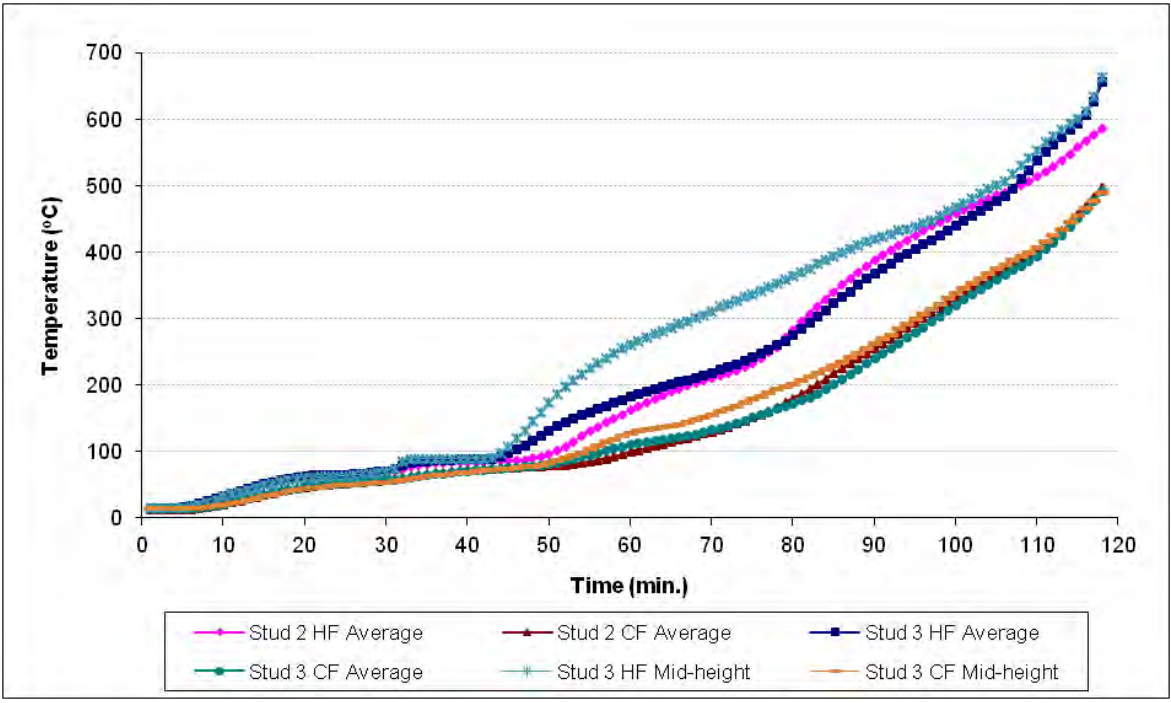

(b) Test 2

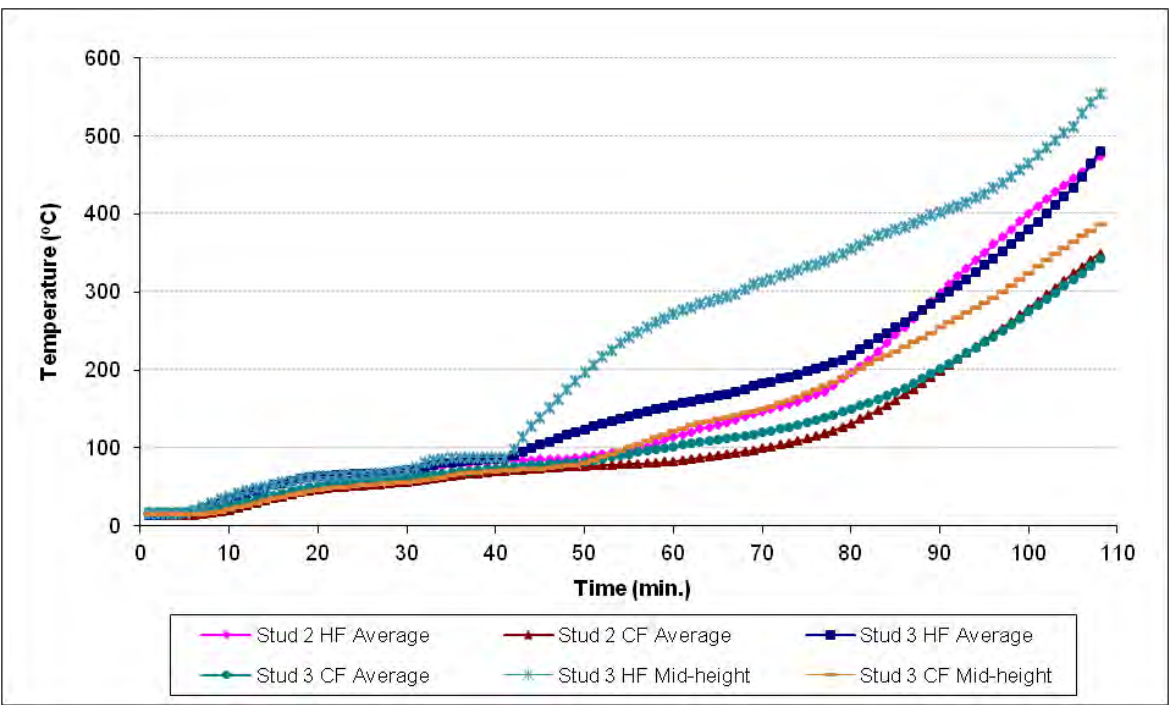

(c) Test 3

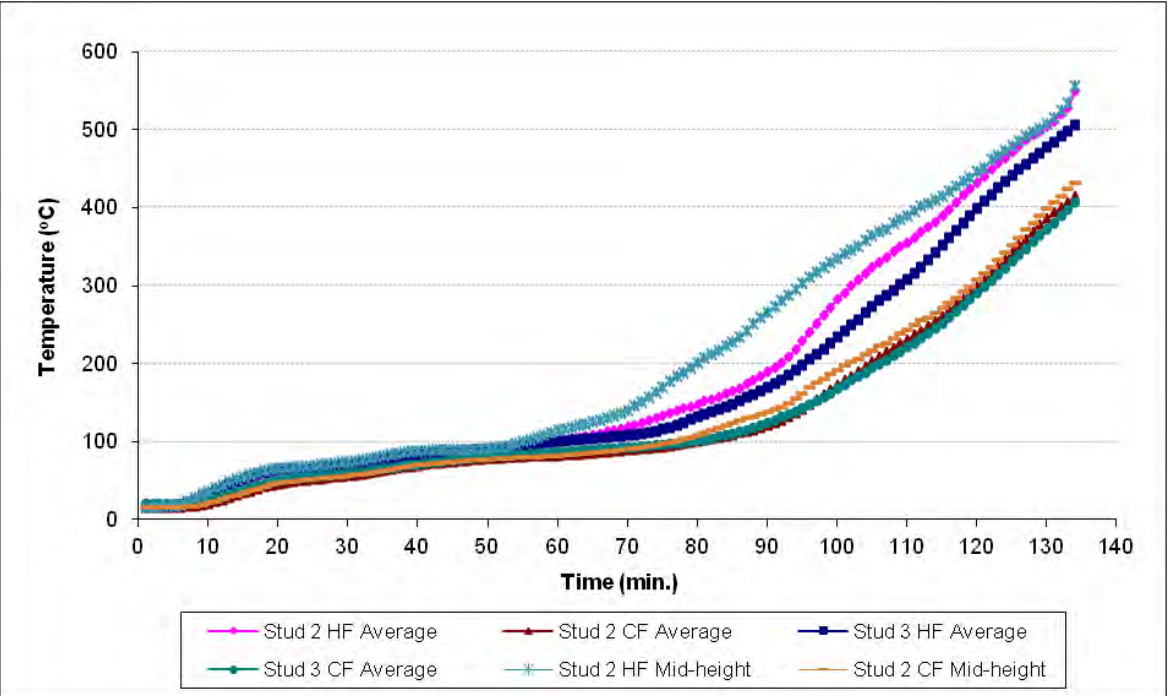

Figure 11: Average Time-Temperature Profiles of the Central Studs Used in FEA $\mathrm{HF}$ - Hot flange; $\mathrm{CF}$ - Cold flange. 
Fringe: Load, Step1, TotalTime=1., Deformation, Displacements, Magnitude, (NON-LAYERED)

Deform: Load, Step1, TotalTime=1., Deformation, Displacements,

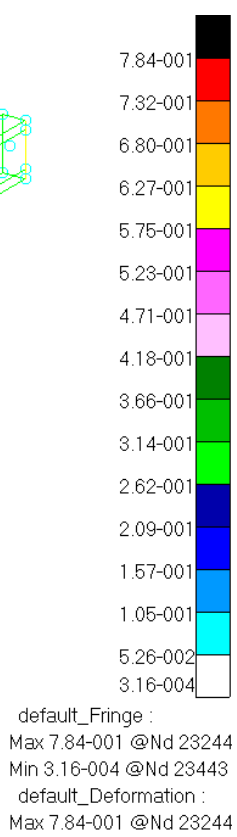

(a) Axial Shortening of Stud 3 after Step 1 (Axial Compressive Load)

Patran 2008r1 01-Oct-10 14:04:59

Fringe: S3Temp, Step2, TotalTime=115.91_32, Deformation, Displacements, Magnitude, (NON-LAYERED)

Deform: S3Temp. Step2,TotalTime=115.91_32, Deformation. Displacements,

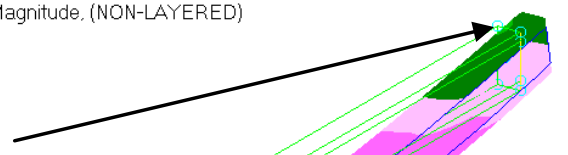

Thermal expansion

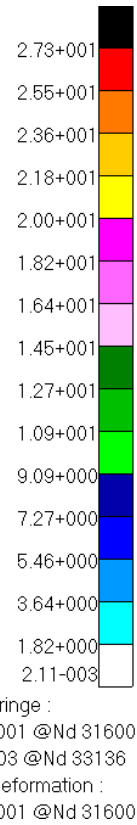

(b) Thermal Bowing and Expansion of Stud 3 after 115 minutes of Step 2 (Temperature)

Figure 12: FEA Results for Stud 3 of Test 1 under Transient State Conditions 
(a) Test 1

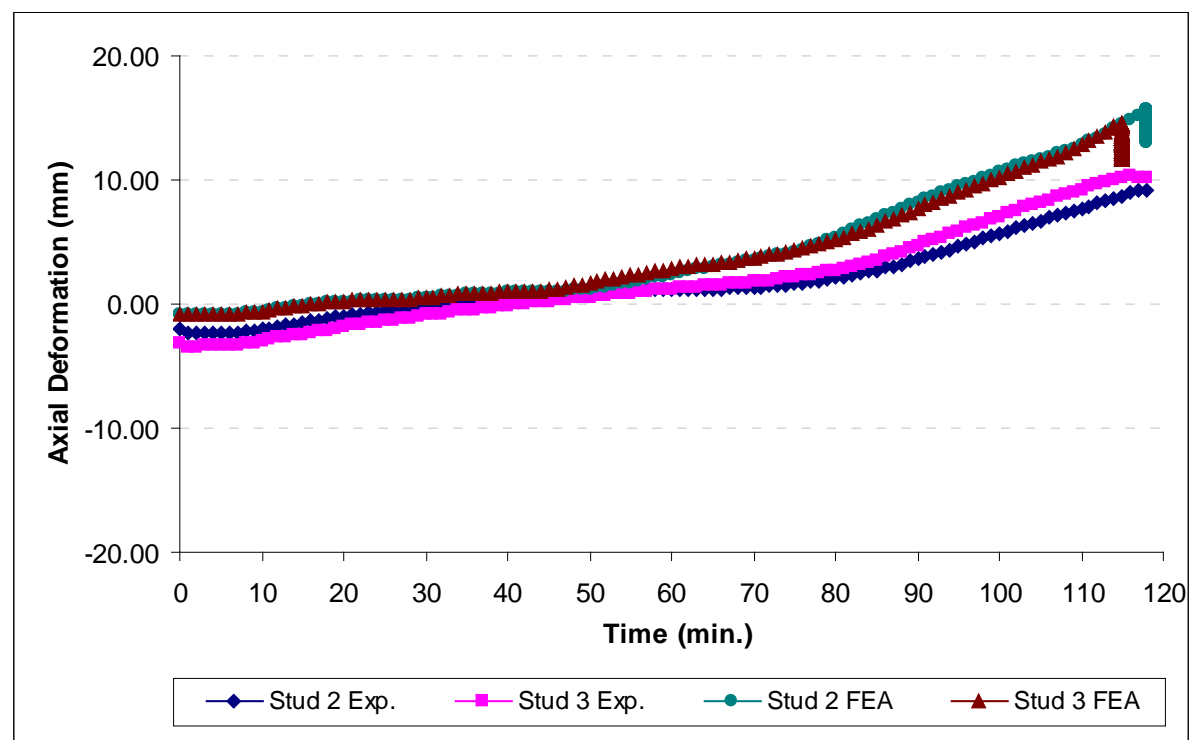

(b) Test 2

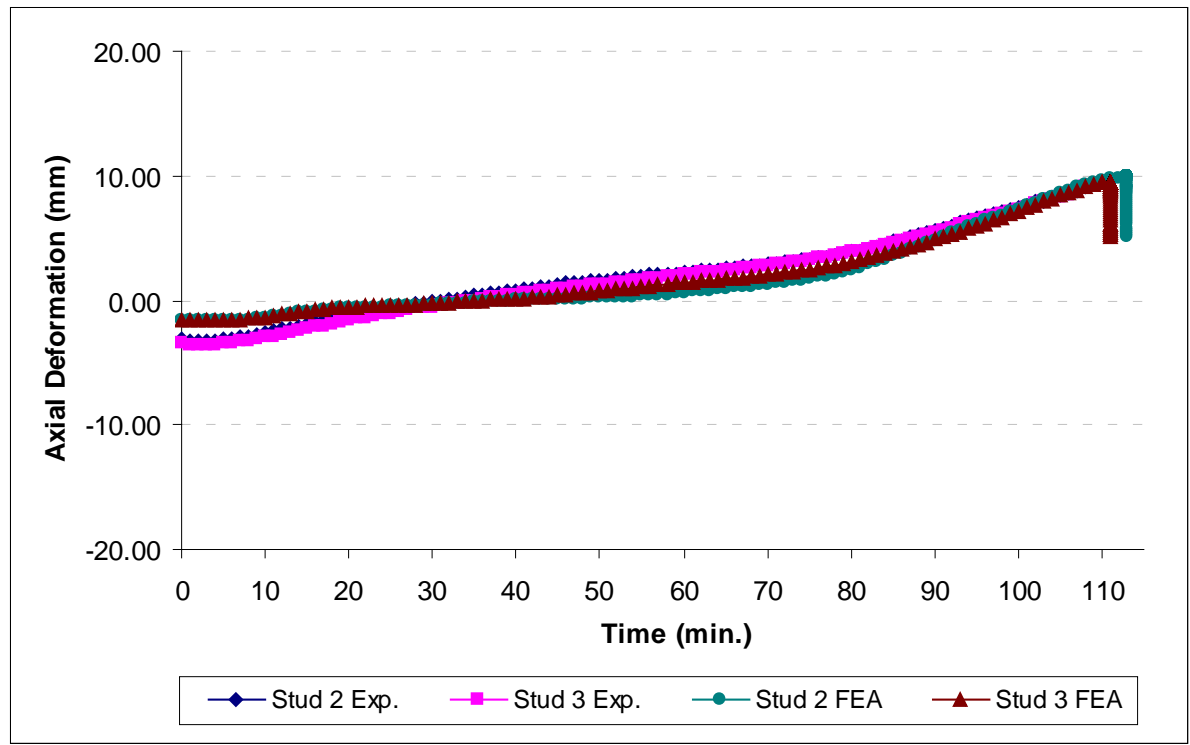

(c) Test 3

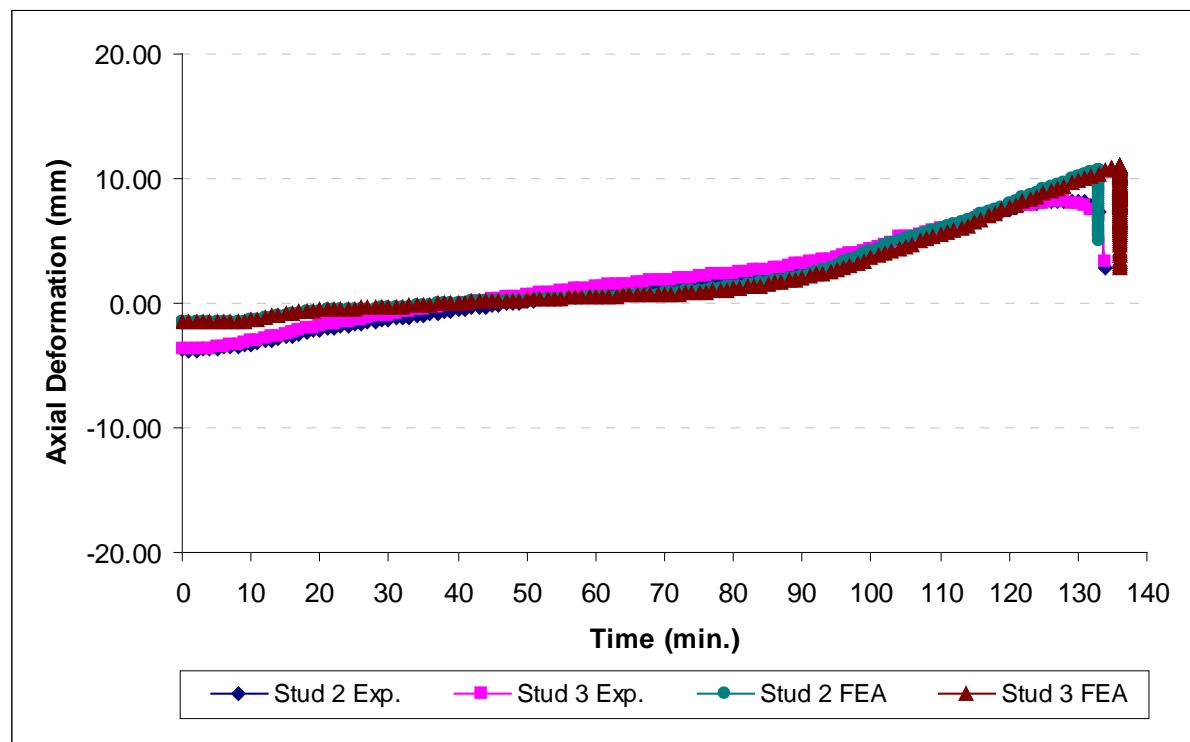

Figure 13: Variation of Axial Deformation with Time under Transient State Conditions 
(a) Test 1

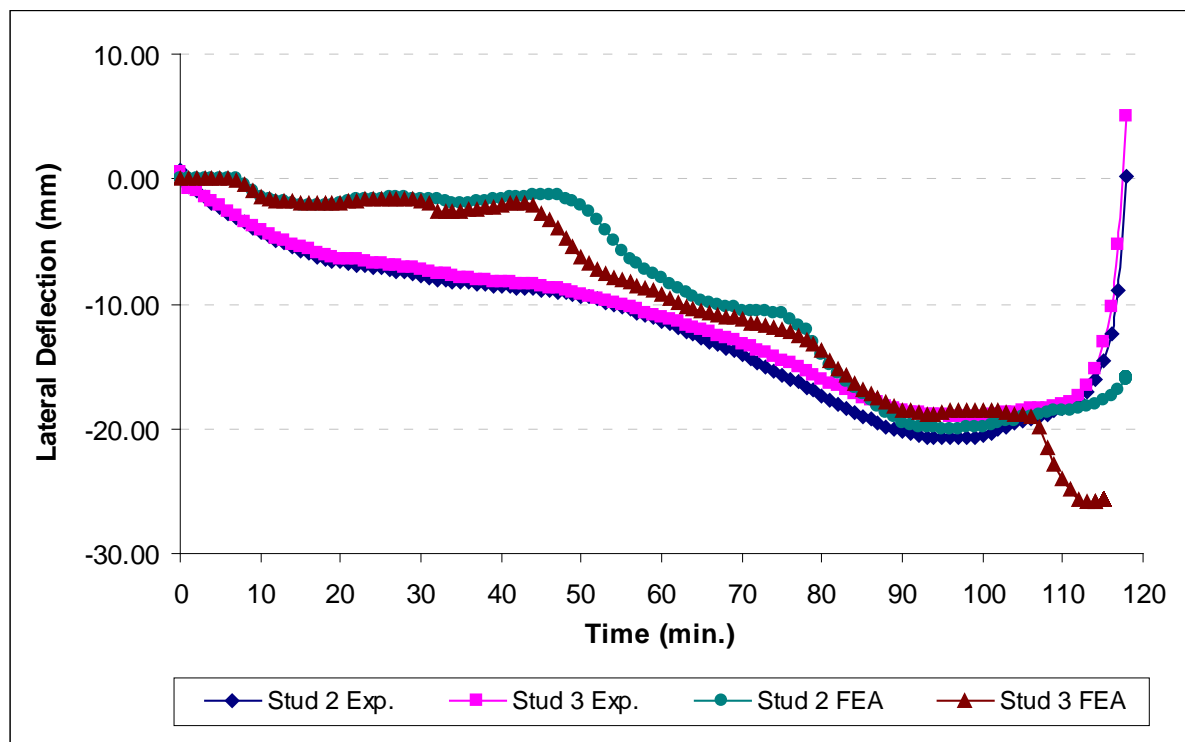

(b) Test 2

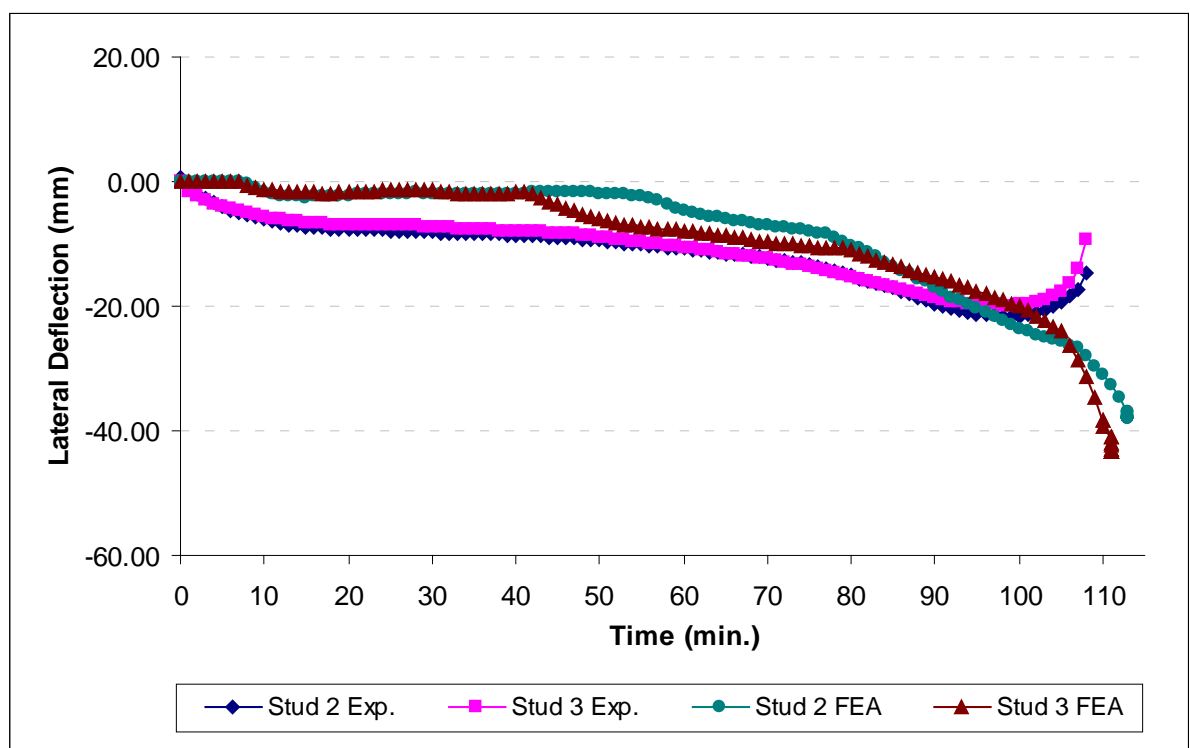

(c) Test 3

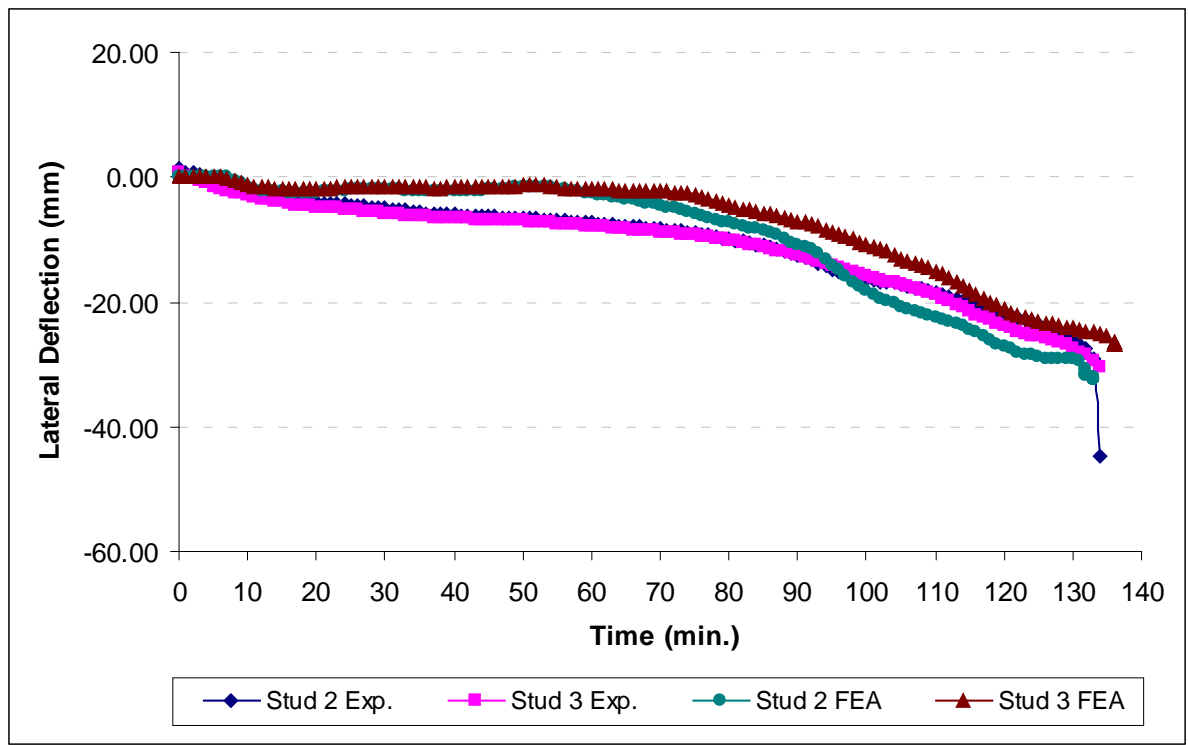

Figure 14: Variation of Lateral Deflection with Time under Transient State Conditions 


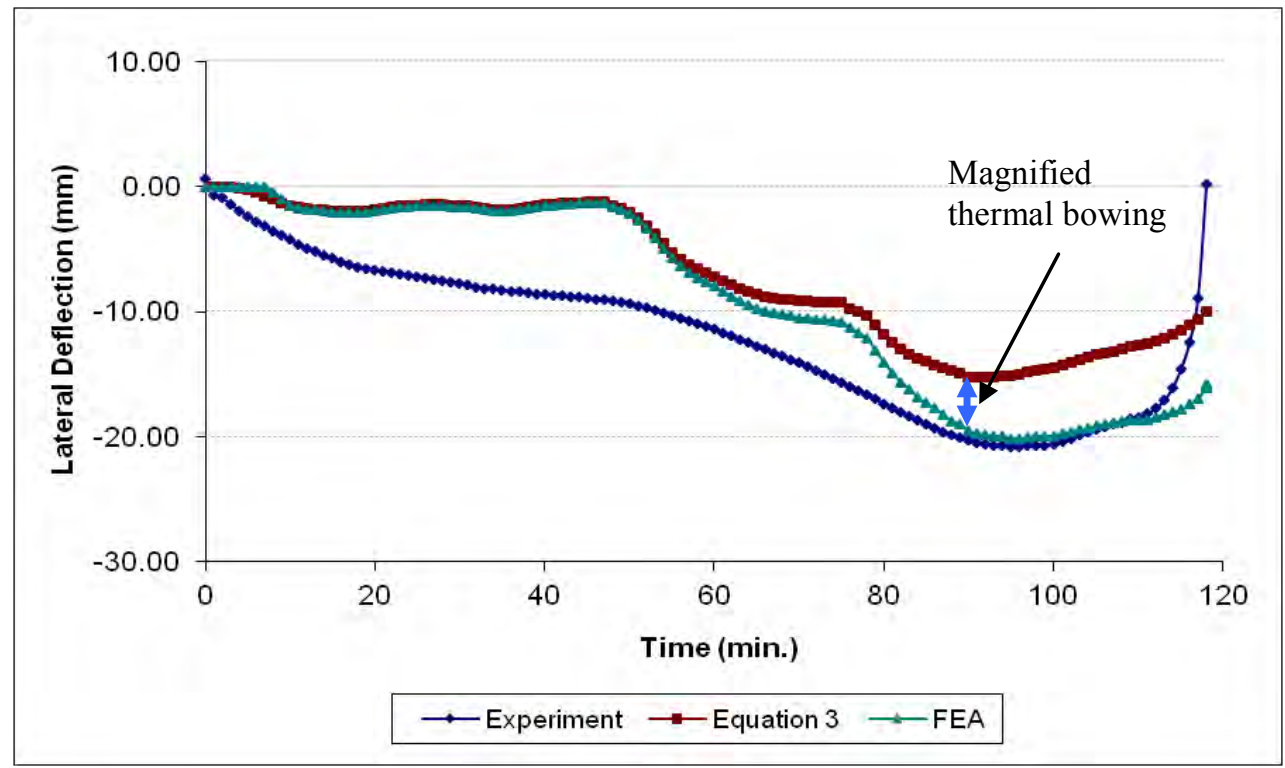

Figure 15: Prediction of Lateral Deflection at Mid-height for Stud 2 of Test 1 under Transient State Conditions
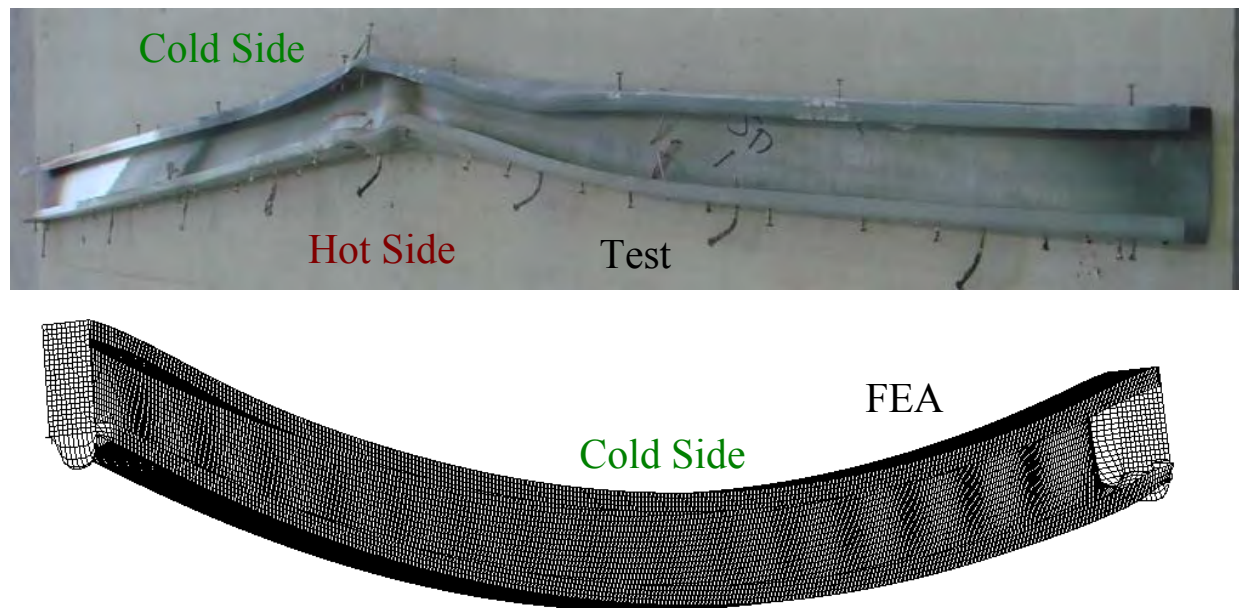

Figure 16: Failure Modes from Test and FEA for Stud 3 of Test 1 under Transient State Conditions 


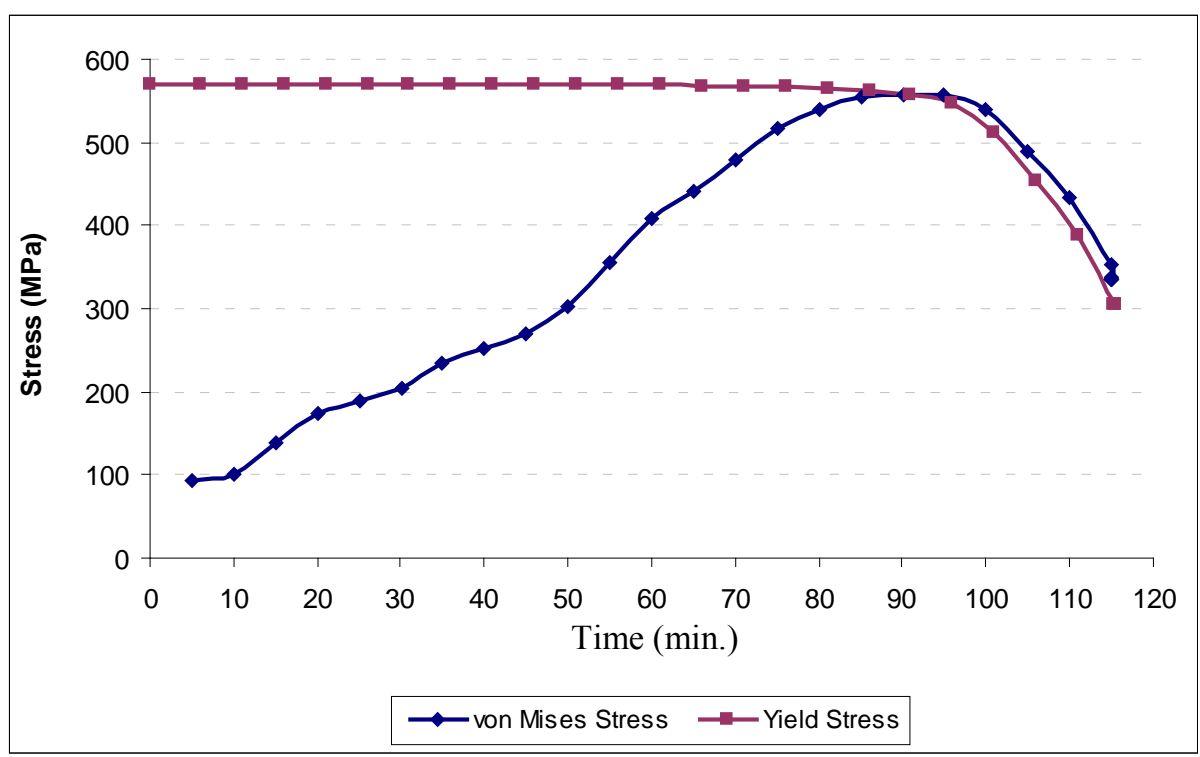

Figure 17: Variation of Yield Stress and von Mises stress from FEA for Stud 3 of Test 1 under Transient State Conditions

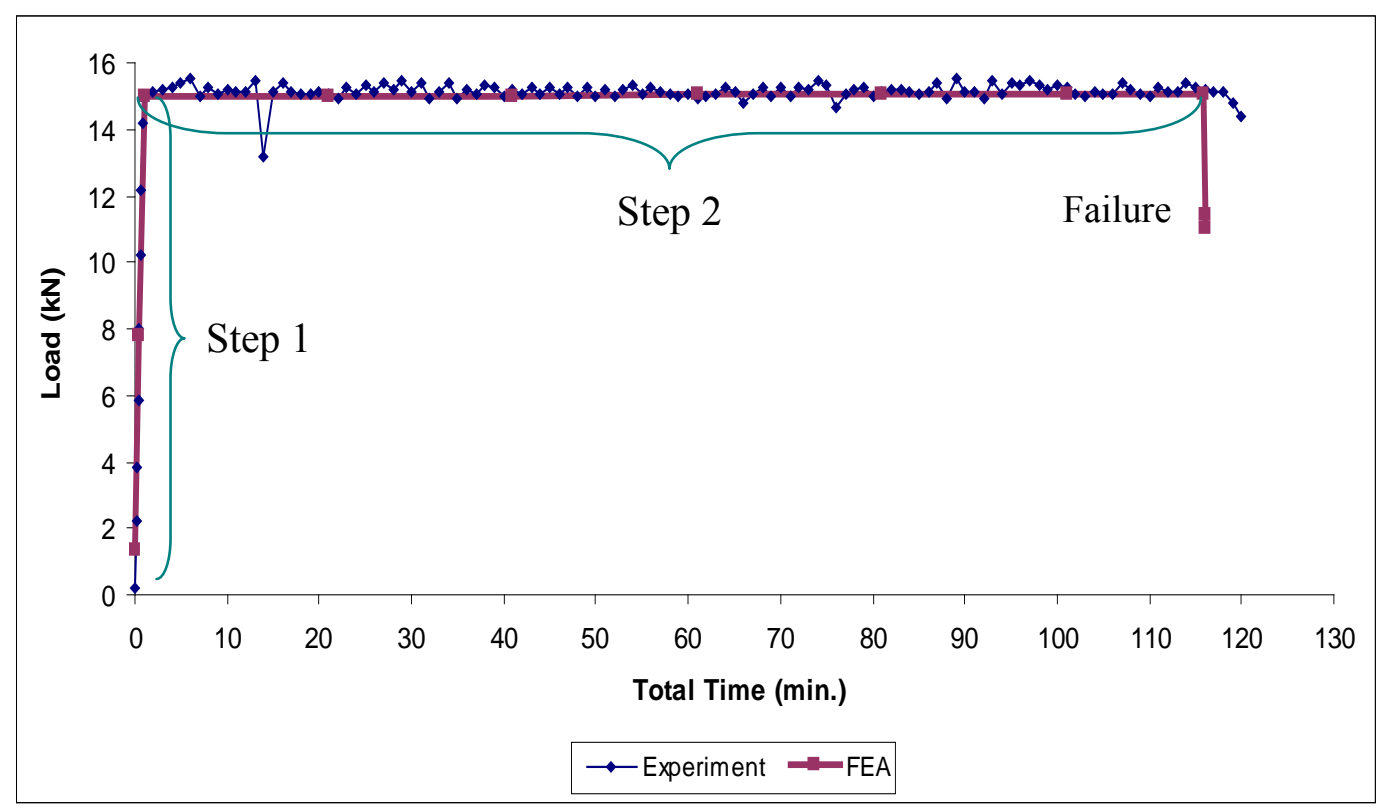

Figure 18: Variation of Applied Load from Test 1 and FEA under Transient State Conditions 


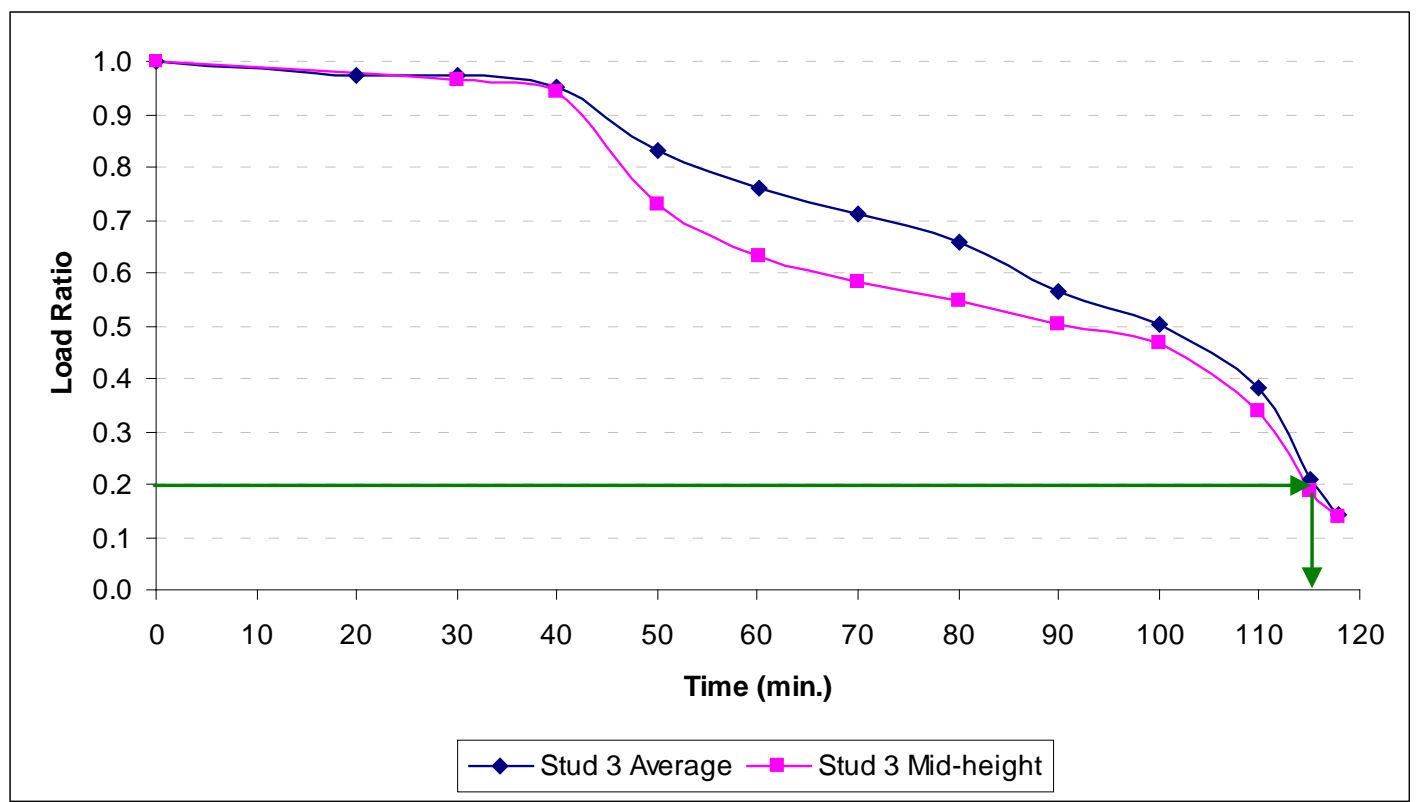

(a) Variation of load ratio with time

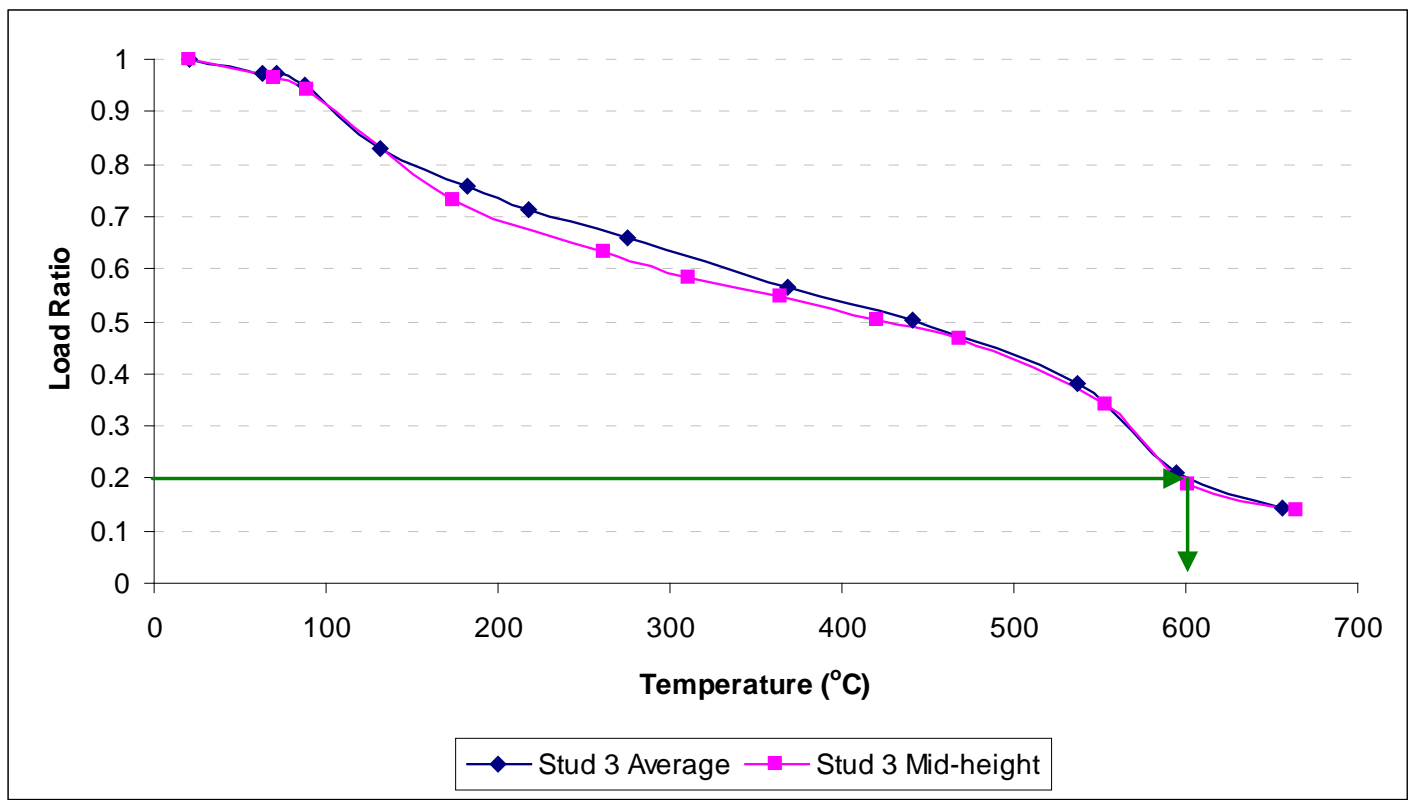

(b) Variation of load ratio with hot flange temperature

Figure 19: FEA Results for Stud 3 of Test 1 under Steady State Conditions 

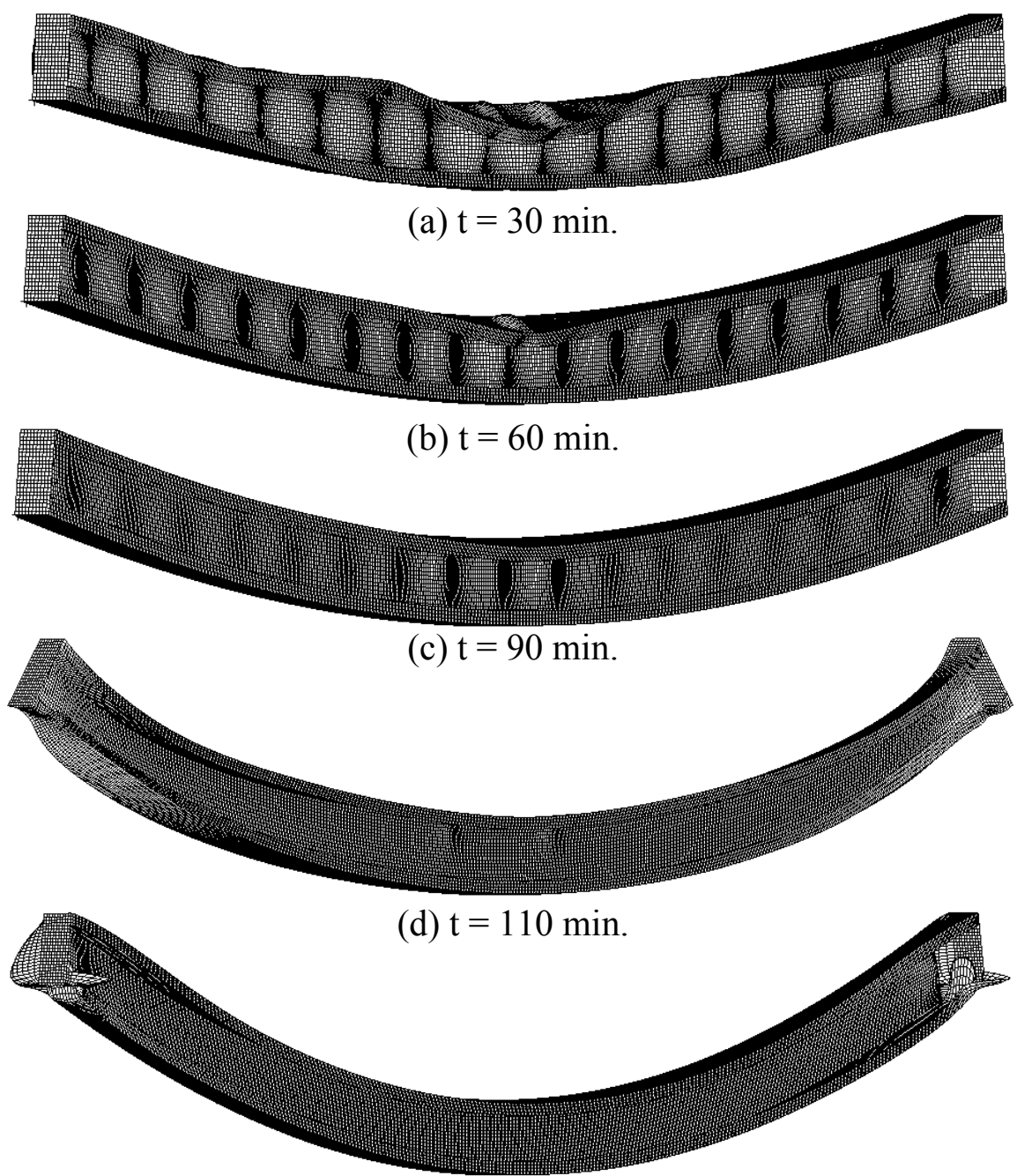

(e) $\mathrm{t}=118 \mathrm{~min}$.

Figure 20: Failure Modes from FEA for Stud 3 of Test 1 under Steady State Conditions 


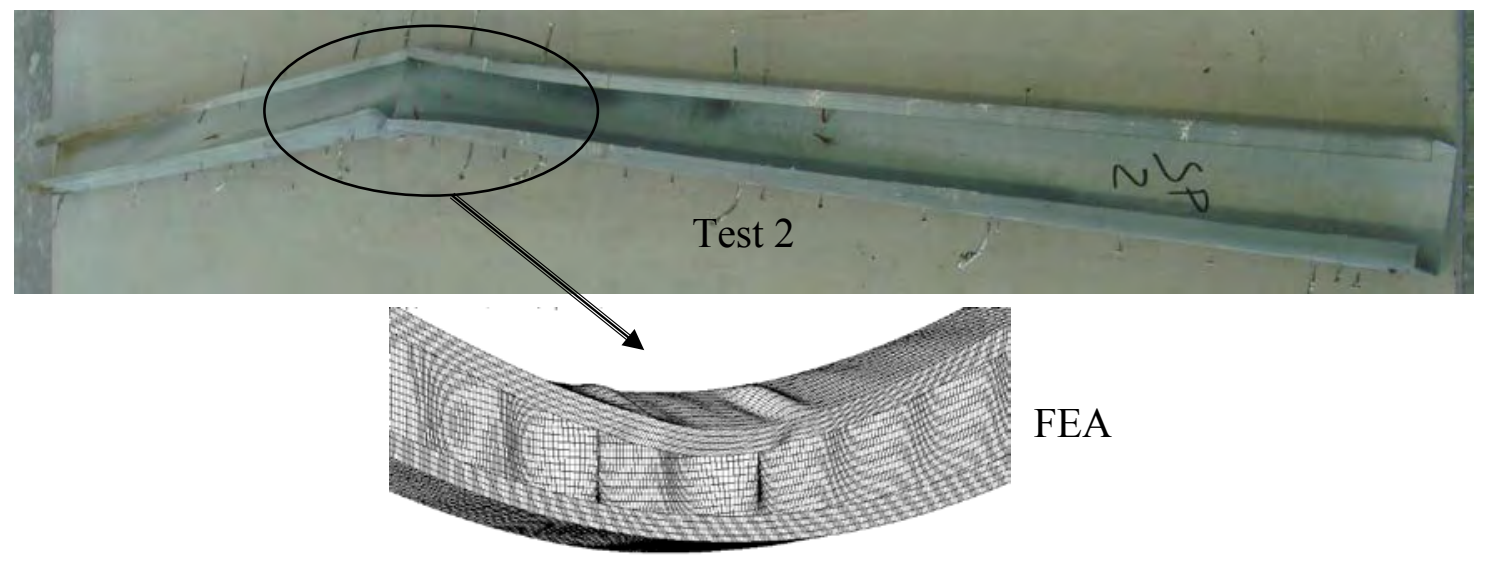

(a) Stud 3 of Test 2

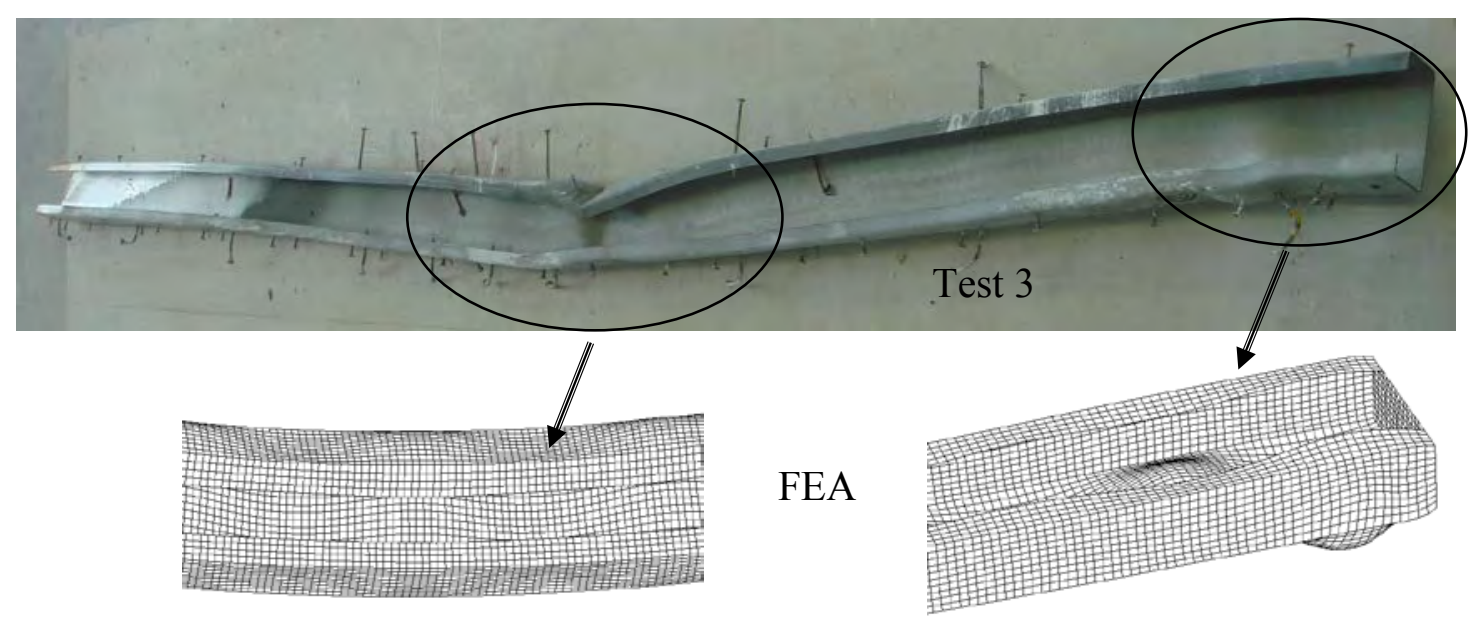

(b) Stud 2 of Test 3

Figure 21: Failure Modes from Test and FEA under Steady State Condition 
(a) Test $1^{*}$

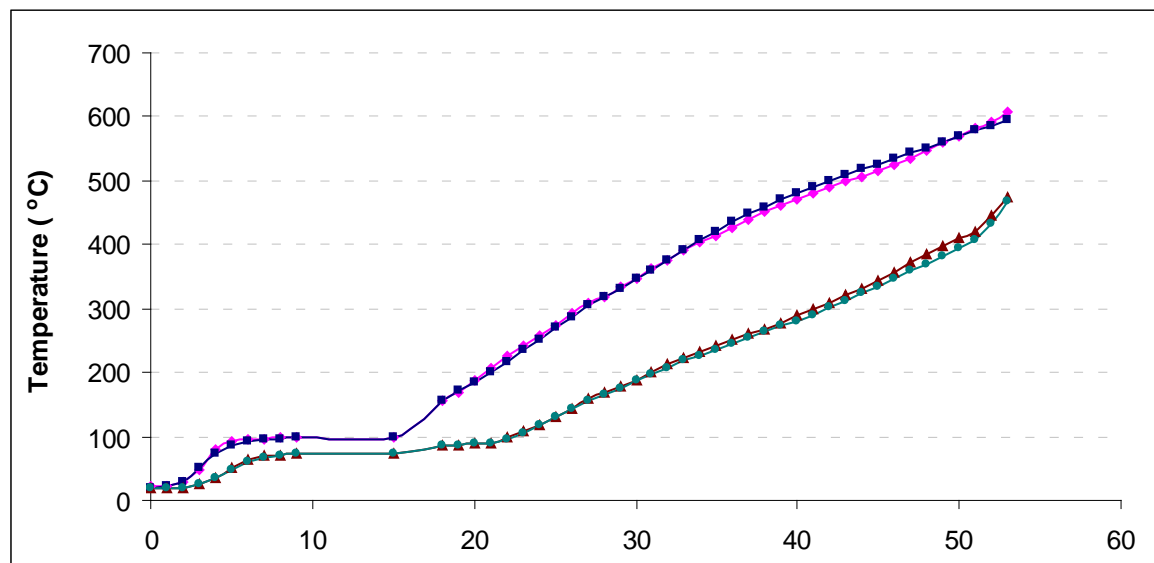

(b) Test 2*

(c) Test $3 *$
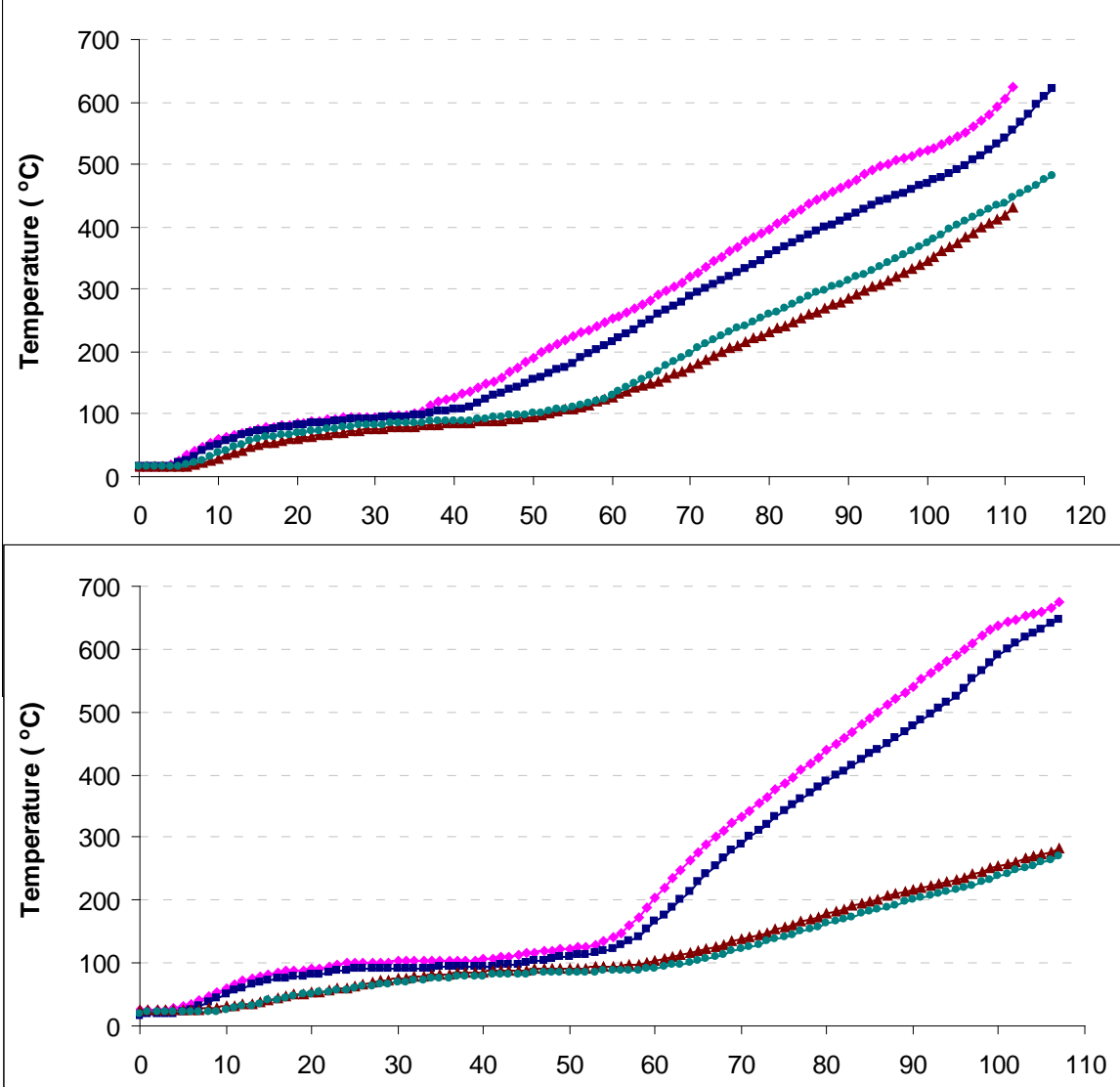

(d) Test 4*

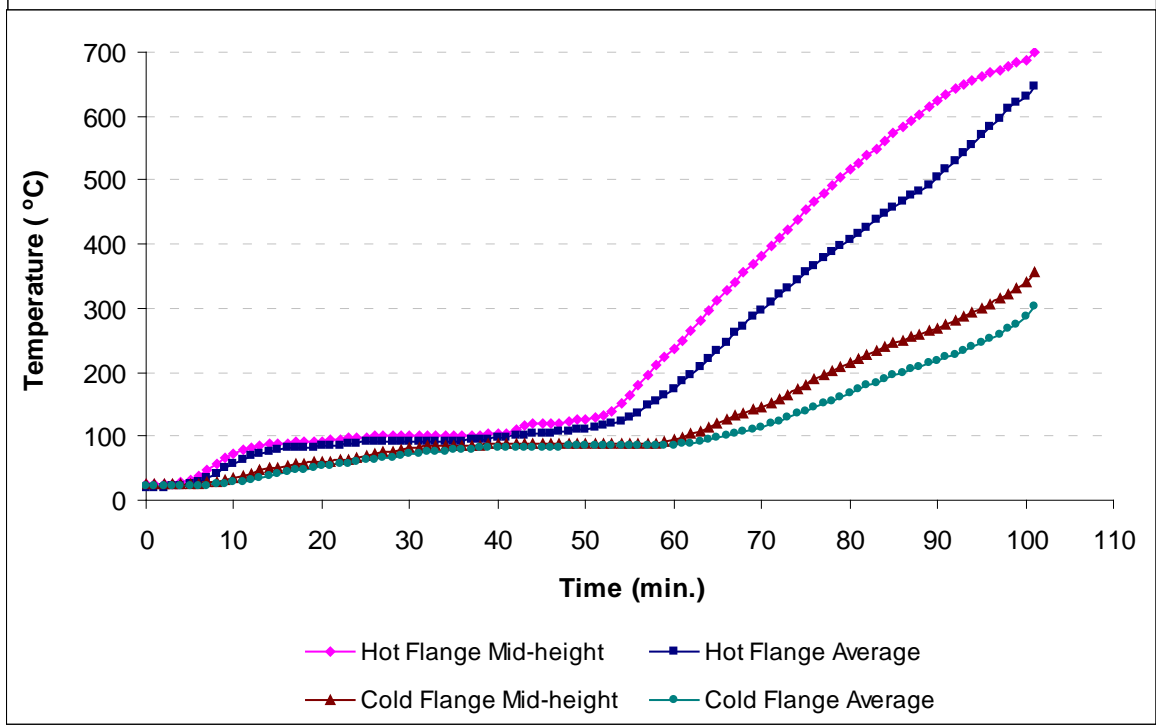


Figure 22: Time-Temperature Profiles Used in FEA for Tests 1* to 7*

(e) Test 5*

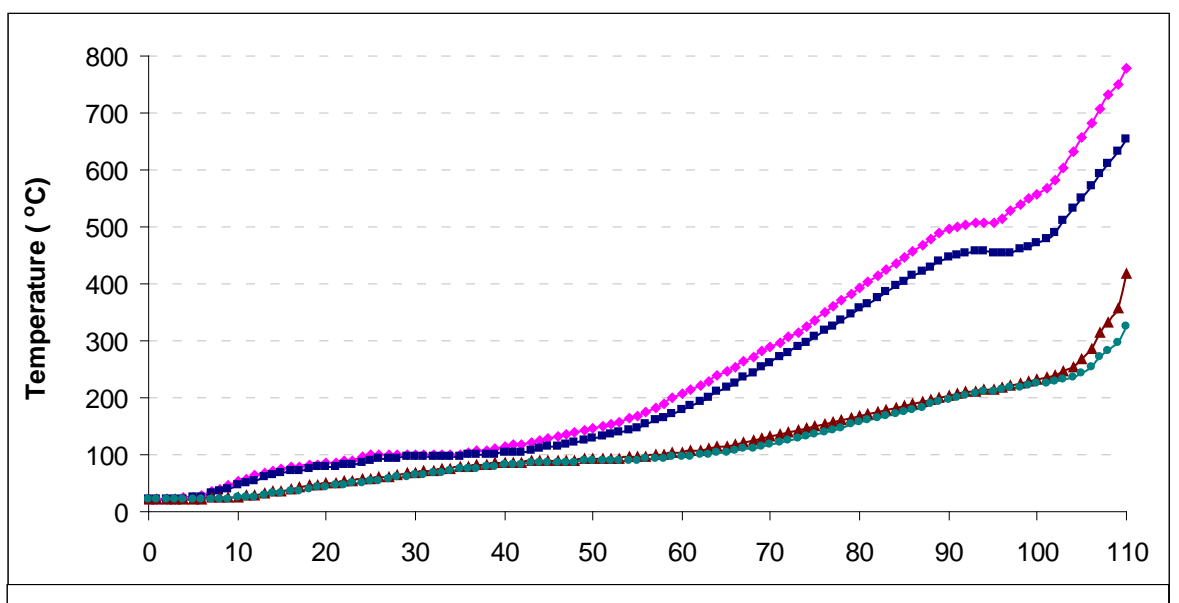

(f) Test 6*

(g) Test $7 *$

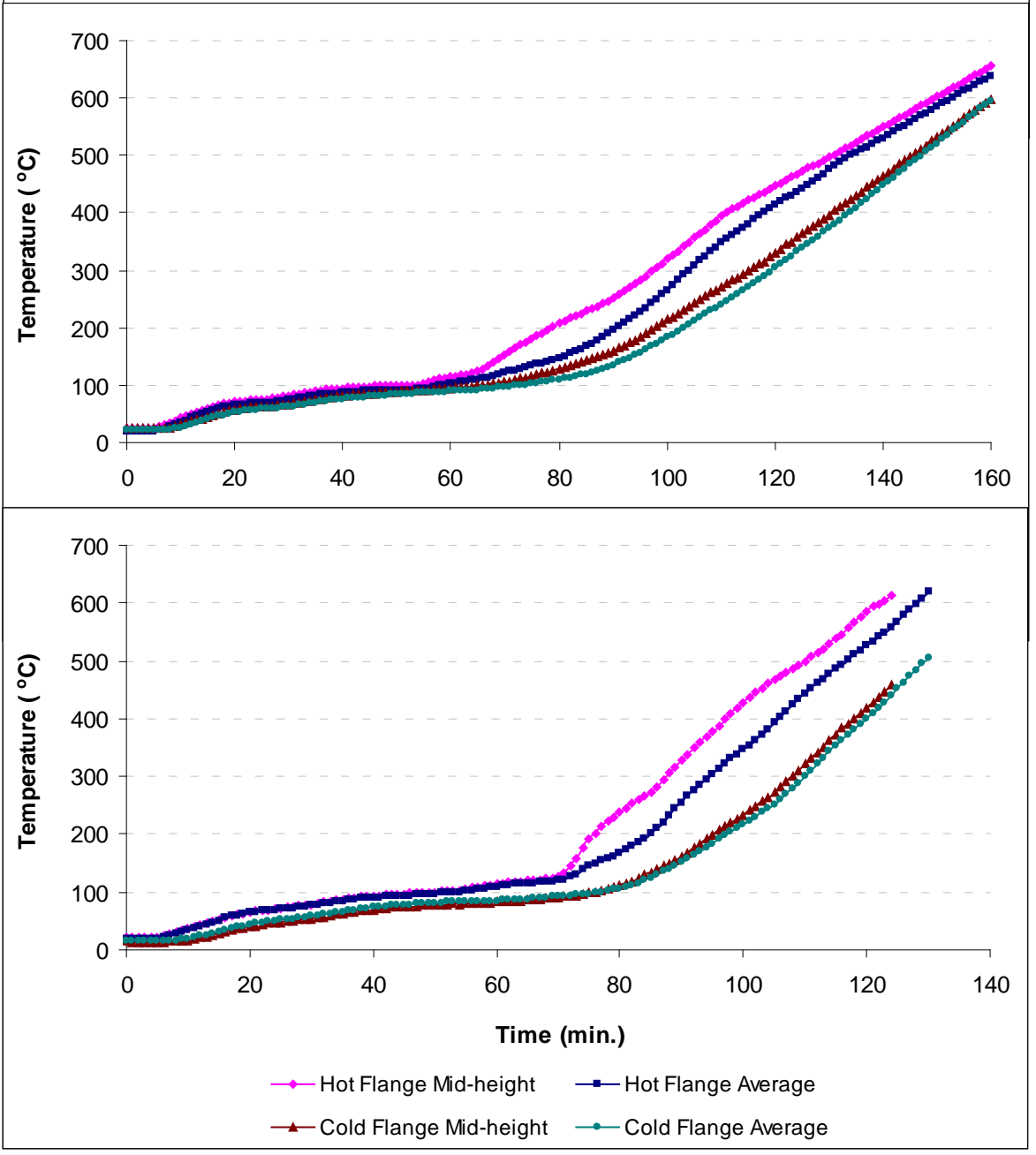

Figure 22: Time-Temperature Profiles Used in FEA for Tests 1* to 7* 


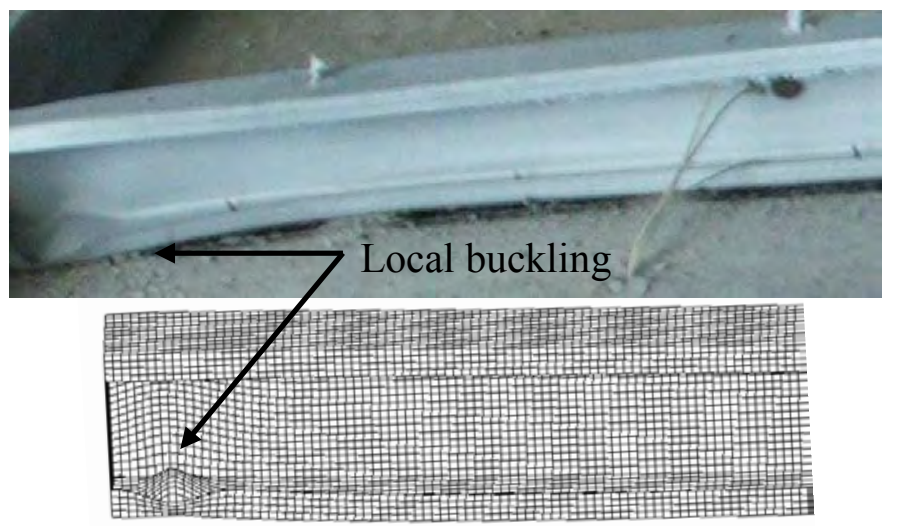

(a) Stud 2 of Test $1 *$
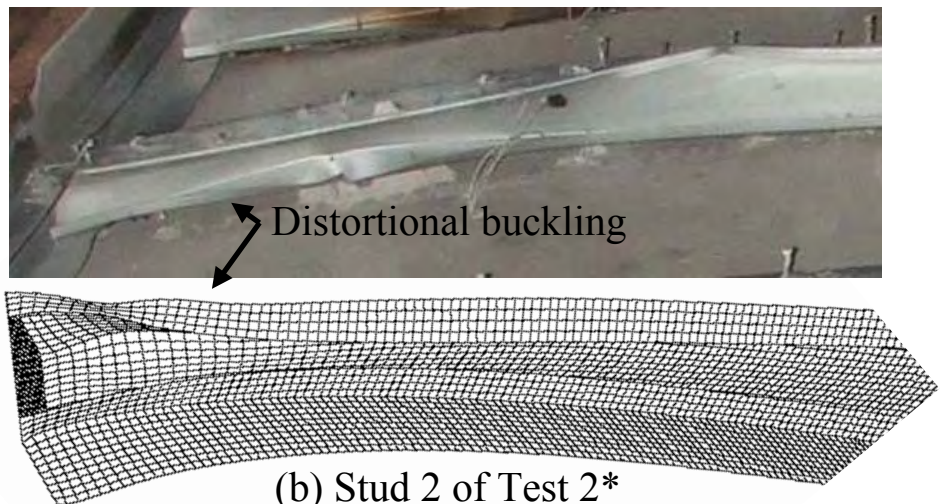

(b) Stud 2 of Test 2*

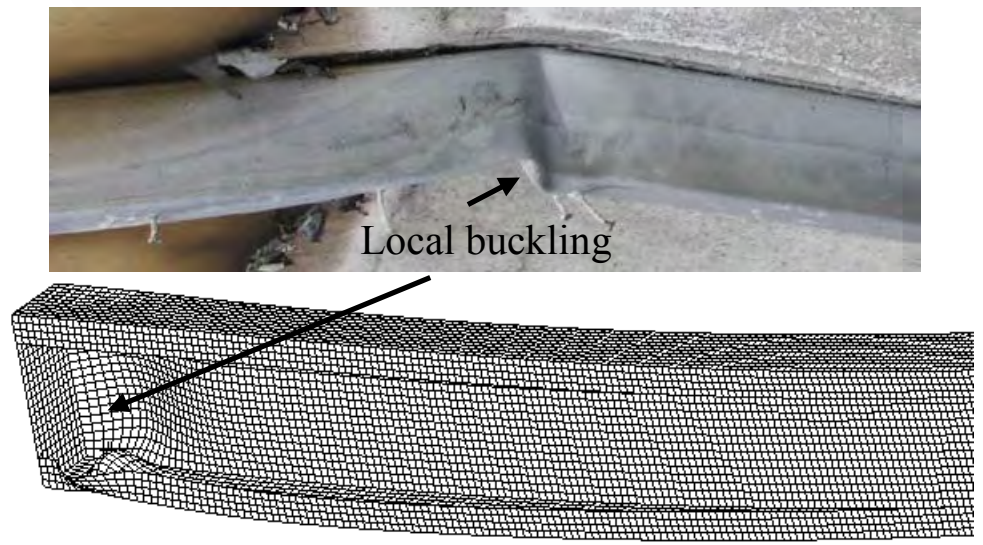

(c) Stud 2 of Test 3*

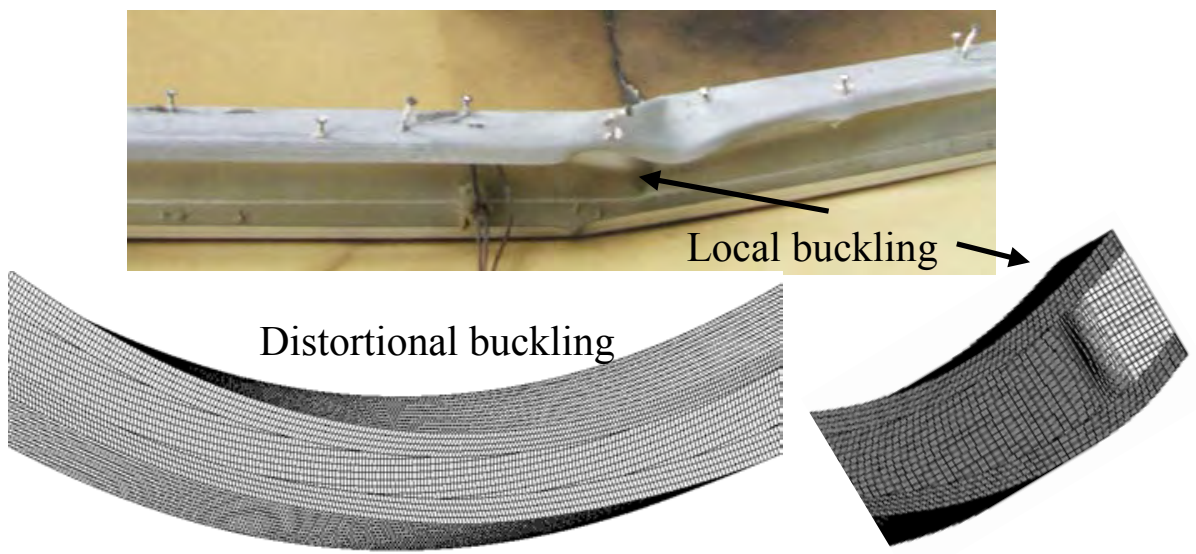

(d) Stud 2 of Test 4* 
Figure 23: Failure Modes from Test and FEA under Steady State Conditions

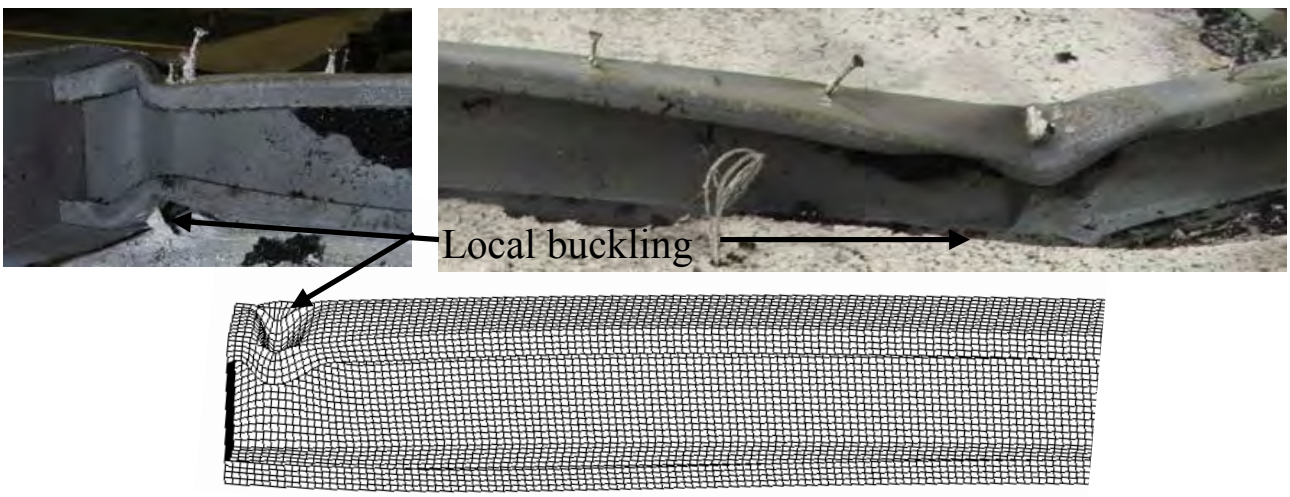

(e) Stud 3 of Test $5^{*}$
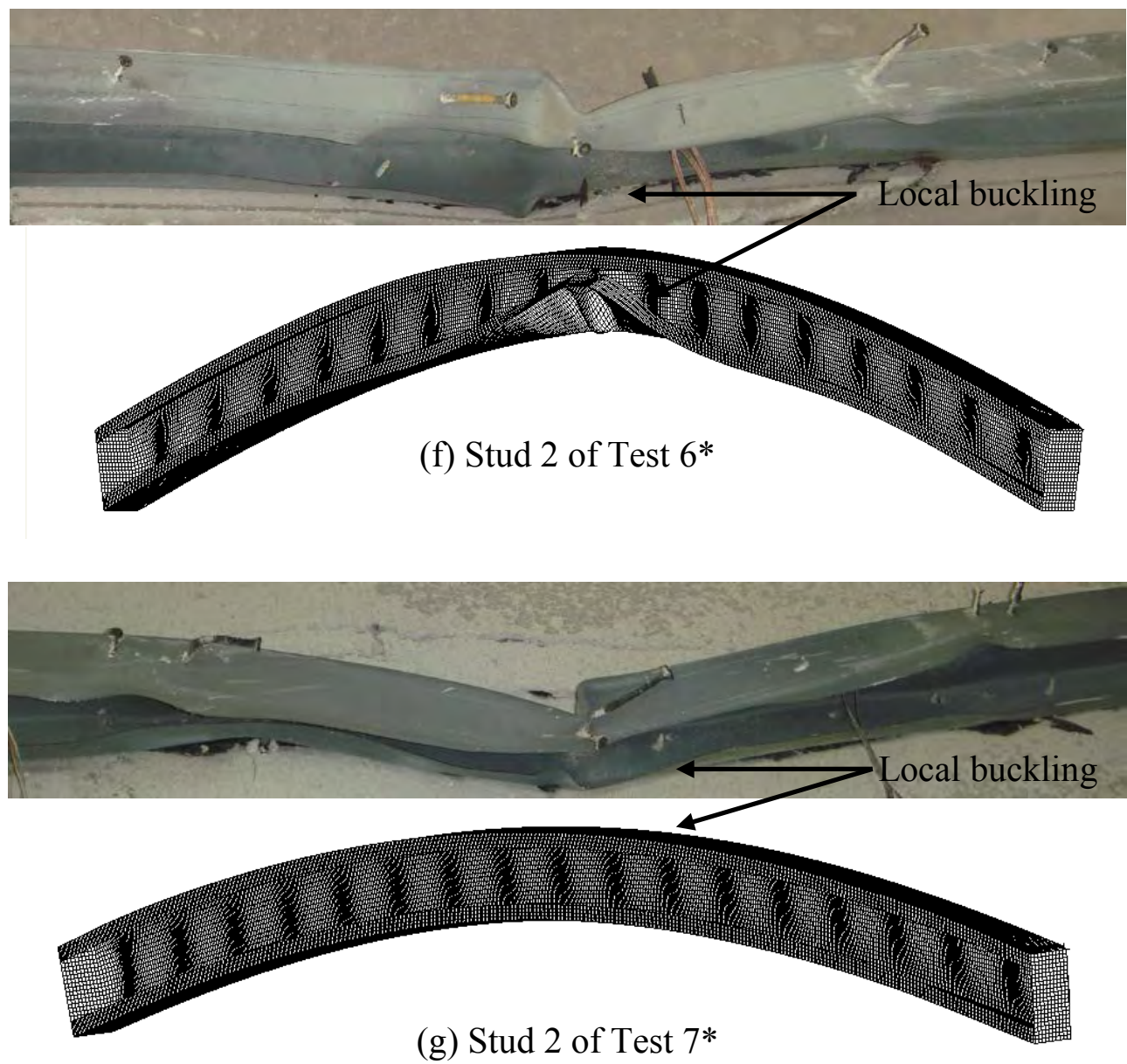

Figure 23: Failure Modes from Test and FEA under Steady State Conditions 


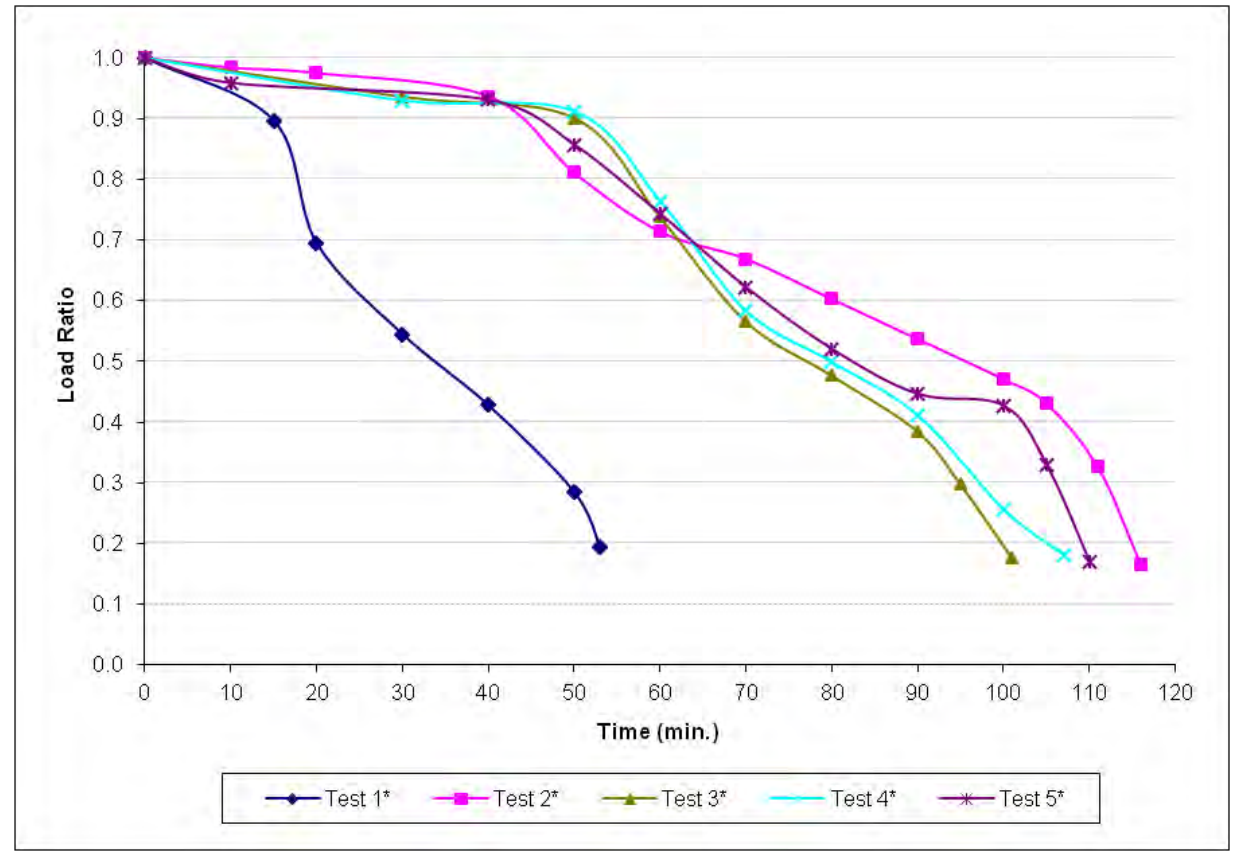

(a) LSF walls with single and double plasterboards with and without cavity insulation

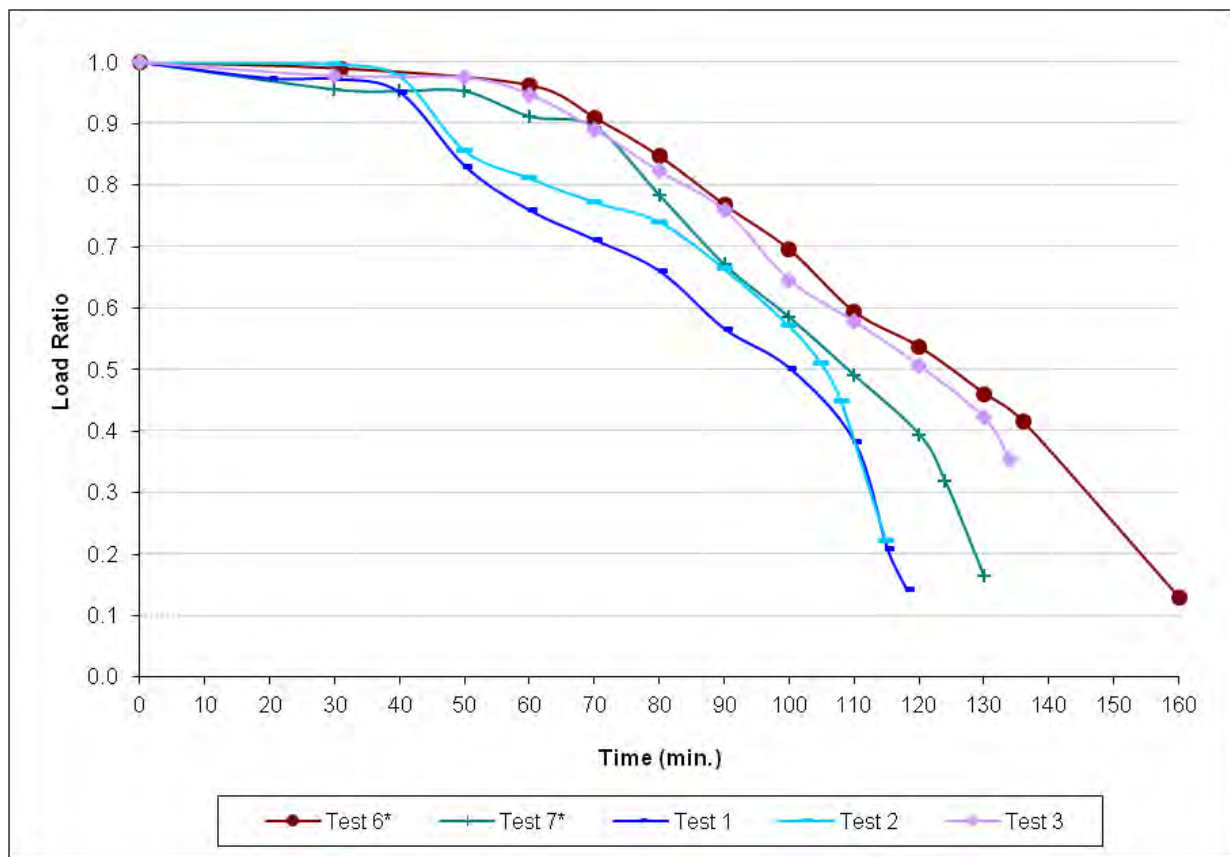

(b) LSF walls with external insulation with different load ratios

Figure 24: Variation of Load Ratio with Time under Steady State Conditions using Average Temperature of the Critical Stud 


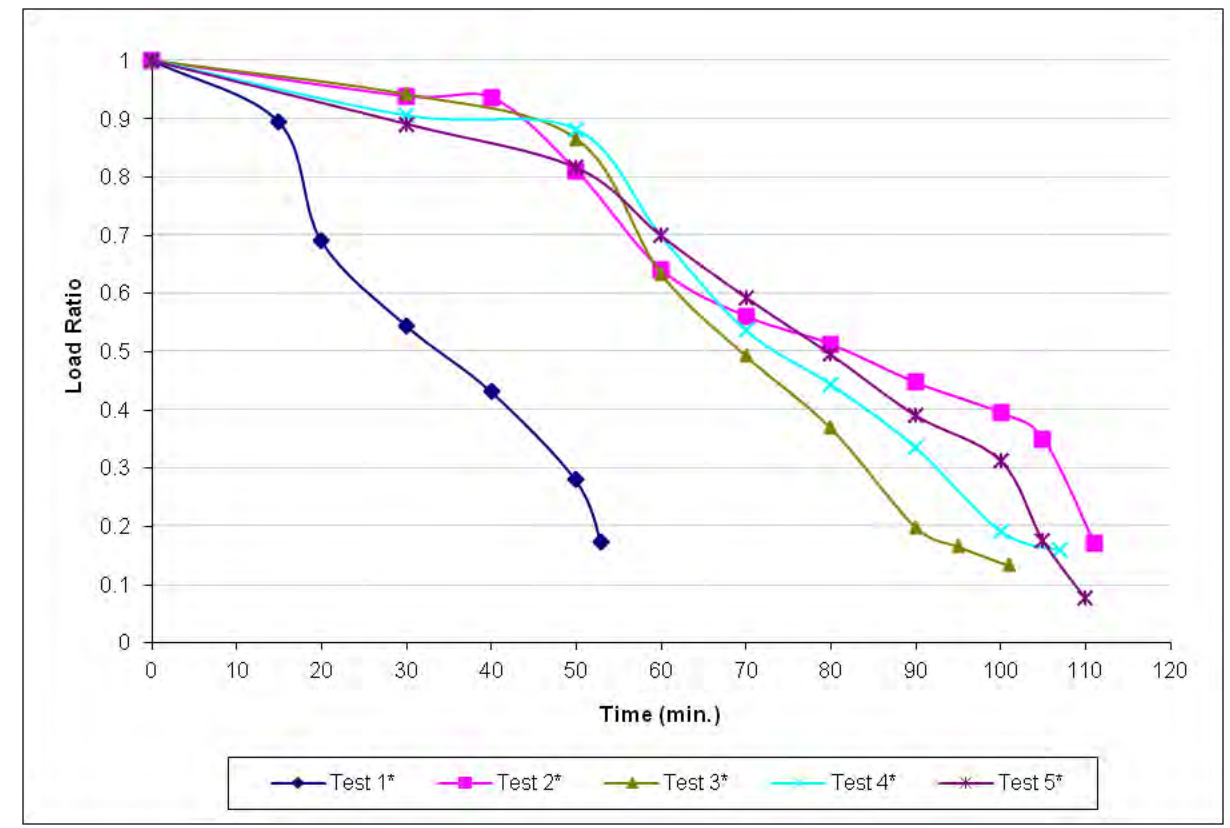

(a) LSF walls with single and double plasterboards with and without cavity insulation

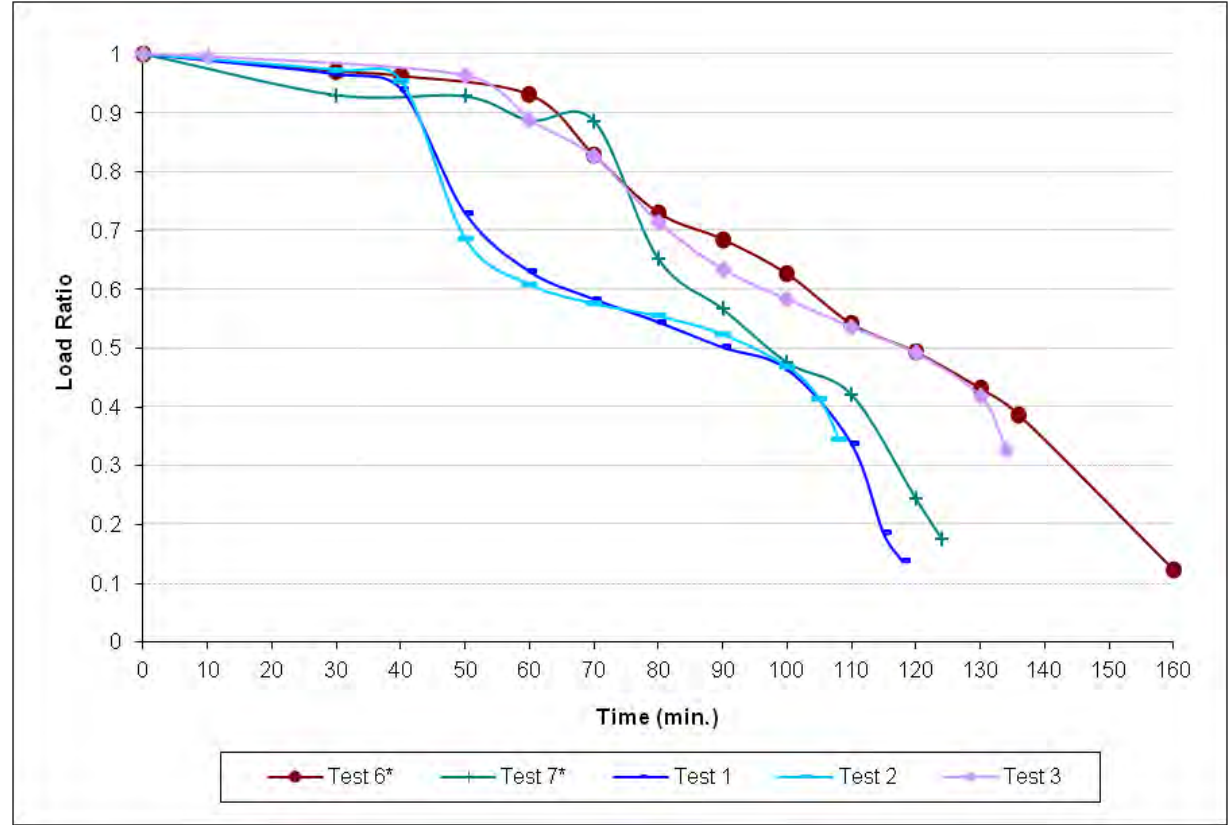

(b) LSF walls with external insulation with different load ratios

Figure 25: Variation of Load Ratio with Time under Steady State Conditions using Mid-height Temperature of the Critical Stud 


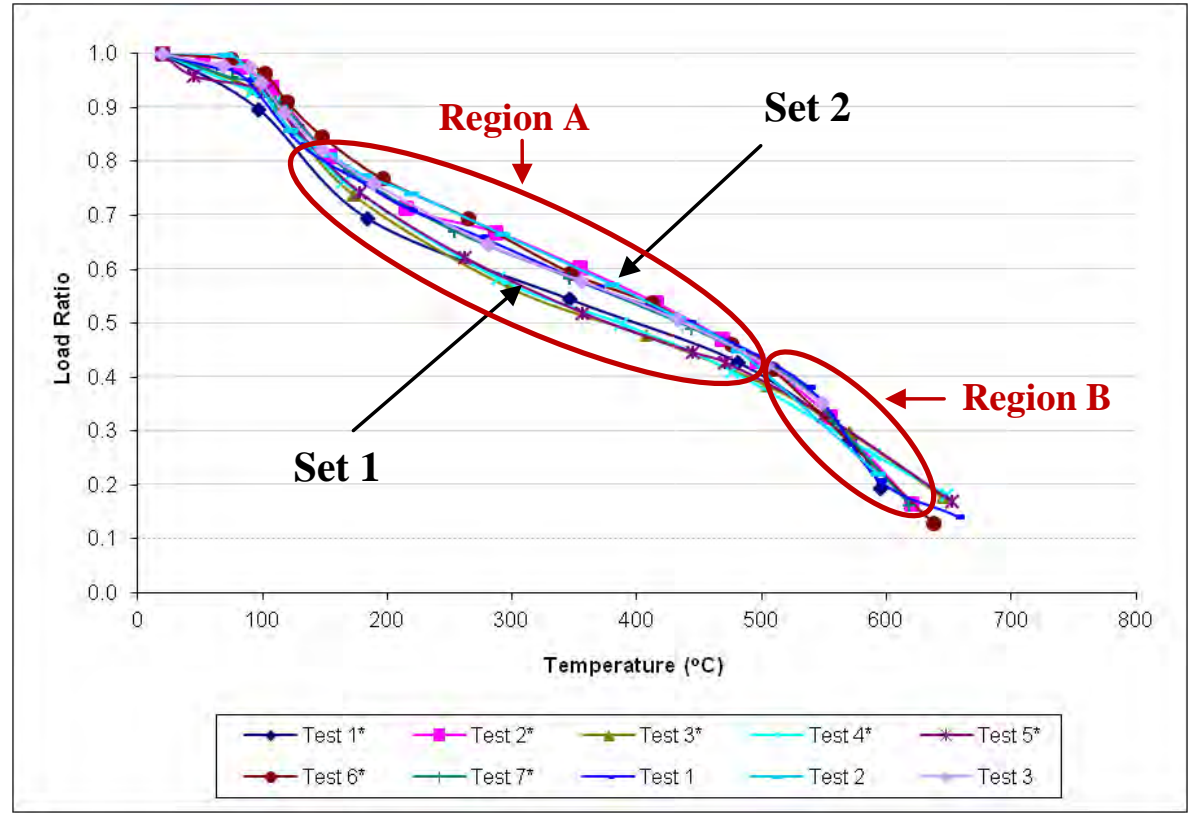

(a) Using average temperature along the stud

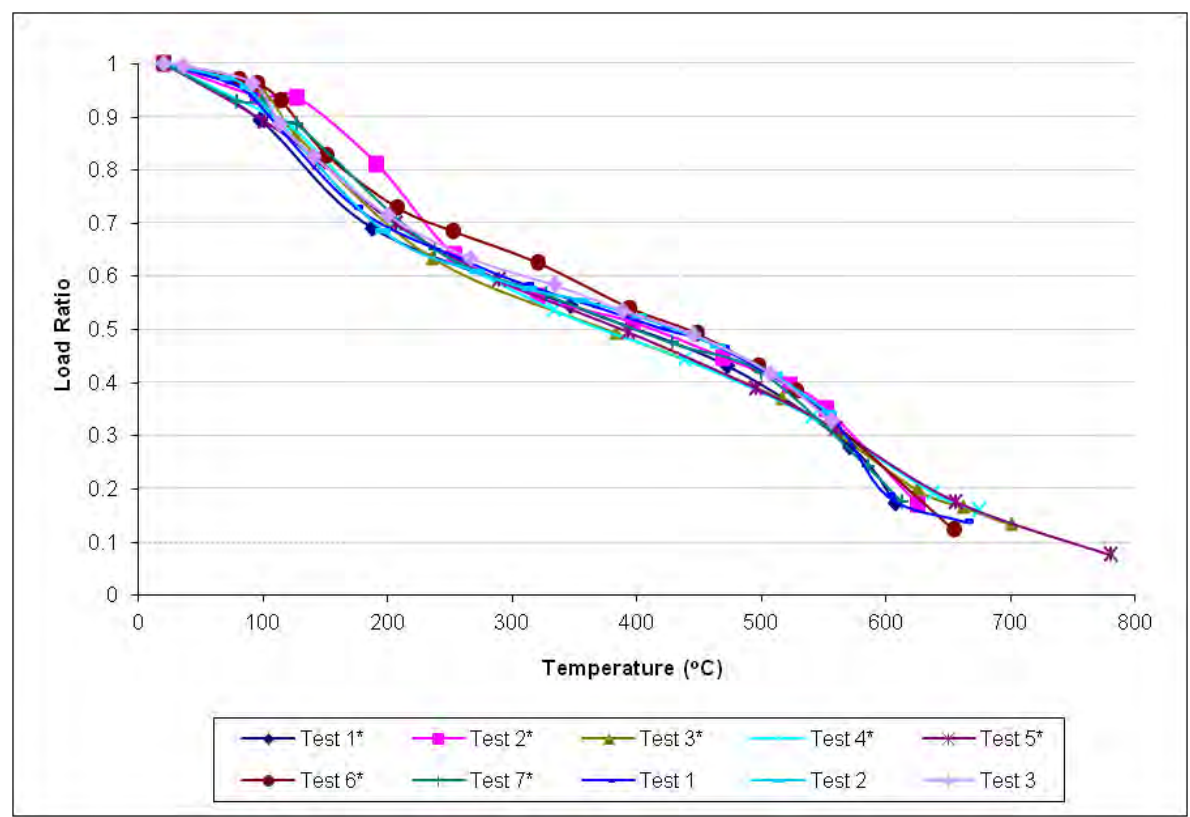

(b) Using mid-height temperature of the stud

Figure 26: Variation of Load Ratio with Hot Flange Temperature from FEA under Steady State Conditions 